\title{
Assessing small-scale deformation and stability of landfast ice on seasonal timescales through L-band SAR interferometry and inverse modeling
}

\author{
Dyre O. Dammann ${ }^{1}$, Hajo Eicken ${ }^{1,2}$, Franz J. Meyer ${ }^{1}$, Andrew R. Mahoney ${ }^{1}$ \\ ${ }^{1}$ Geophysical Institute, University of Alaska Fairbanks, Fairbanks, Alaska \\ 903 Koyukuk Drive, Fairbanks, AK 99775, USA \\ ${ }^{2}$ International Arctic Research Center, Fairbanks, Alaska \\ 930 Koyukuk Drive, Fairbanks, AK 99775, USA
}

dodammann@alaska.edu, heicken@alaska.edu, fjmeyer@alaska.edu, armahoney@alaska.edu

\section{Corresponding author:}

Dyre O. Dammann

903 Koyukuk Drive, Fairbanks, AK 99775, dodammann@alaska.edu, +1 9074745648

\section{Keywords:}

Remote sensing; Ice trafficability; Arctic; Synthetic aperture radar interferometry;

Landfast ice; Sea ice; ALOS PALSAR; Ice stability; Surface deformation; Ice dynamics 


\begin{abstract}
Rapid environmental change and increases in use of shorefast ice by industry and coastal communities highlight the need for an approach to accurately assess landfast sea-ice stability on seasonal timescales. While stability can sometimes be inferred from field measurements, current methods are lacking robustness and the ability to be automated and applied over large areas and long time scales to ensure safety and document change in the context of transportation, indigenous ice uses and industrial development. This paper introduces an inverse model capable of reconstructing three-dimensional deformation fields from one-dimensional interferometric L-band Synthetic Aperture Radar (SAR) phase patterns. We apply this method at three landfast ice locations on the Alaska Beaufort Sea coast near Barrow and Prudhoe Bay. We find the small-scale displacements estimated from the model consistent with regional patterns of ice motion. Our study suggests that interferometry can provide planning and decision-support information for ice road development and structures operating within ice. Moreover, InSAR can potentially increase our understanding of sea ice on a fundamental level in terms of large-scale stability and long-term changes in ice dynamics.
\end{abstract}




\section{Introduction}

Arctic sea ice has undergone major rapid change in recent decades [Comiso and Hall, 2014; Meier et al., 2014; Stroeve et al., 2012] with potentially widespread, global consequences. Direct impacts of a changing sea-ice cover are expected along circumpolar coastlines where both communities and industry depend on coastal and landfast sea ice as a platform vital to Indigenous cultures, subsistence, transportation, and industrial development [Eicken et al., 2009]. In Alaska, much of the landfast ice extent has also rapidly declined during the past decades [Fienup-Riordan and Rearden, 2010; Mahoney et al., 2014].

A major concern for ice users from both communities and industry is ice movement, which can eventually lead to reduced load bearing capacity through fracturing or even destabilization of landfast ice [BP, 2013; Eicken et al., 2011; George et al., 2004; Potter et al., 1981]. The use of ice by the oil and gas industry for transportation and as a platform for exploration and staging of equipment requires clear identification of potential hazards [Eicken and Mahoney, 2015; Eicken et al., 2011] derived from smallscale displacements that may lead to cracks, wider openings or foster development of hazardous features such as strudel scour through later drainage through cracks [Dickins et al., 2011].

Evaluations of ice safety based on simple threshold criteria, e.g., with respect to minimum thickness [Finucane and Scher, 1983; USACE, 2002] are not applicable with respect to ice stability. However, it is clearly recognized that ice roads should try to avoid areas of ice movement and rely on routes over stable ice [Bashaw et al., 2013; Potter et al., 1981]. The challenge for industrial use of sea ice as a platform is to make accurate 
measurements evaluating suitability and safety of the ice in a cost-effective and timely manner [Mesher et al., 2008]. Moreover, information related to stability is often difficult to acquire and, due to the many factors that govern ice stability, typically requires measurements of the actual movement and deformation of the ice. Recent technological advances in satellite remote sensing set the stage for more thorough, quantitative and cost-effective alternatives to aerial reconnaissance often used to detect critical ice features [Potter et al., 1981].

Synthetic aperture radar interferometry (InSAR) has shown promise as a technique to detect differential displacement in the landfast sea ice [Dammert et al., 1998; Meyer et al., 2011; Morris et al., 1999; Vincent et al., 2004] down to the millimeter-scale in areas with small-scale deformation (mm- to m-scale) and no active ridging deformation, wet precipitation, or significant melt or desalination processes, which will change the scattering processes. These prior InSAR studies over sea ice have all demonstrated the potential value of SAR interferometry in understanding ice dynamics with potential implications for stakeholders. However, there are clear limitations to interpreting the exact $3-\mathrm{d}$ deformation due to preexisting ambiguities resulting from the 1-d phase information [Li et al., 1996]. This study - to our knowledge the first to analyze interferogram fringe patterns over sea ice in a rigorous manner - aims to develop a method drawing on InSAR data that can be used to evaluate large-scale deformation patterns of the landfast ice and the source of the deformation. Although the application of InSAR may eventually be used to study deformation of mobile pack ice (e.g. Mahoney et al. [2016]) or identify precursors to hazardous events such as ice pileups or breakouts, we will here focus on long temporal baseline InSAR to identify 
regionally persistent deformation processes in landfast ice related to thermal changes, due to ice growth, and external factors such as regional sustained pack ice forcing.

The goal is to develop an approach that can be used to establish a climatology of ice deformation that can be used during planning and execution of on-ice operations, capable of providing guidance on (i) the type of deformation occurring in different regions, (ii) the point in time when the ice is sufficiently stable to significantly reduce risk, and (iii) areas experiencing deformation large enough for substantial cracking and requiring thorough risk assessment on the ground. This method would also create the foundation for a large-scale comparison between models and observations of landfast ice dynamics, a crucial step in validating landfast ice numerical models.

The ice regime evaluated in this study ranges from smooth to severely deformed during early to mid spring before the onset of melt. The absence of both melt and widespread severe deformation events (ridging or lateral deformation $>10 \mathrm{~m}$ ) enables scatterers to stay intact enabling coherent interferogram formation. InSAR is first validated over sea ice as a technique capable of identifying small-scale displacement within the landfast ice (Section 2). Then, a two-dimensional deformation field is produced from the one-dimensional phase measurements using an inverse model constrained to a canonical set of realistic strain mechanisms (Section 3), a technique that is then tested and validated in northern Alaska (Section 4). Model ambiguities and limitations are further discussed in Section 5.

\section{L-band InSAR data for landfast ice analysis}

\subsection{Data}


Synthetic aperture radar interferometry (InSAR) is a technique that measures phase differences between two SAR scenes acquired from two coherent viewing geometries [Bamler and Hartl, 1998; Ferretti et al., 2007]. The observed phase difference can originate from displacement of the scattering surface if measurements were acquired at different times (non-zero temporal baselines) and/or from surface topography if measurements originate from slightly different vantage points (non-zero spatial baselines).

This study utilizes L-band PALSAR-1 Synthetic Aperture Radar (SAR) images acquired by the Japanese Advanced Land Observing Satellite-1 (ALOS-1). PALSAR-1 operated from 2006 - 2011 with a 46-day repeat cycle and in a typical year provided almost complete coverage of the northern Alaska coastline in a four-month period during the landfast ice season (Figure 1). Obtaining coherent interferograms is most likely during this time of year, when the surface of landfast ice is most stable and least affected by thermodynamic and dynamic processes. Interferograms can also often be obtained over landfast ice earlier and later in the spring as well, provided the ice remains stationary and there is no melting, flooding or other significant change at the surface. From all available data, this study selected a series of three interferograms for three areas along the North American Arctic coast including (1) the Alaska Beaufort Sea coast near Barrow, (2) Prudhoe Bay, and (3) Foggy Island Bay (Figure 1). Information about the SAR data used in this study is summarized in Table 1. 


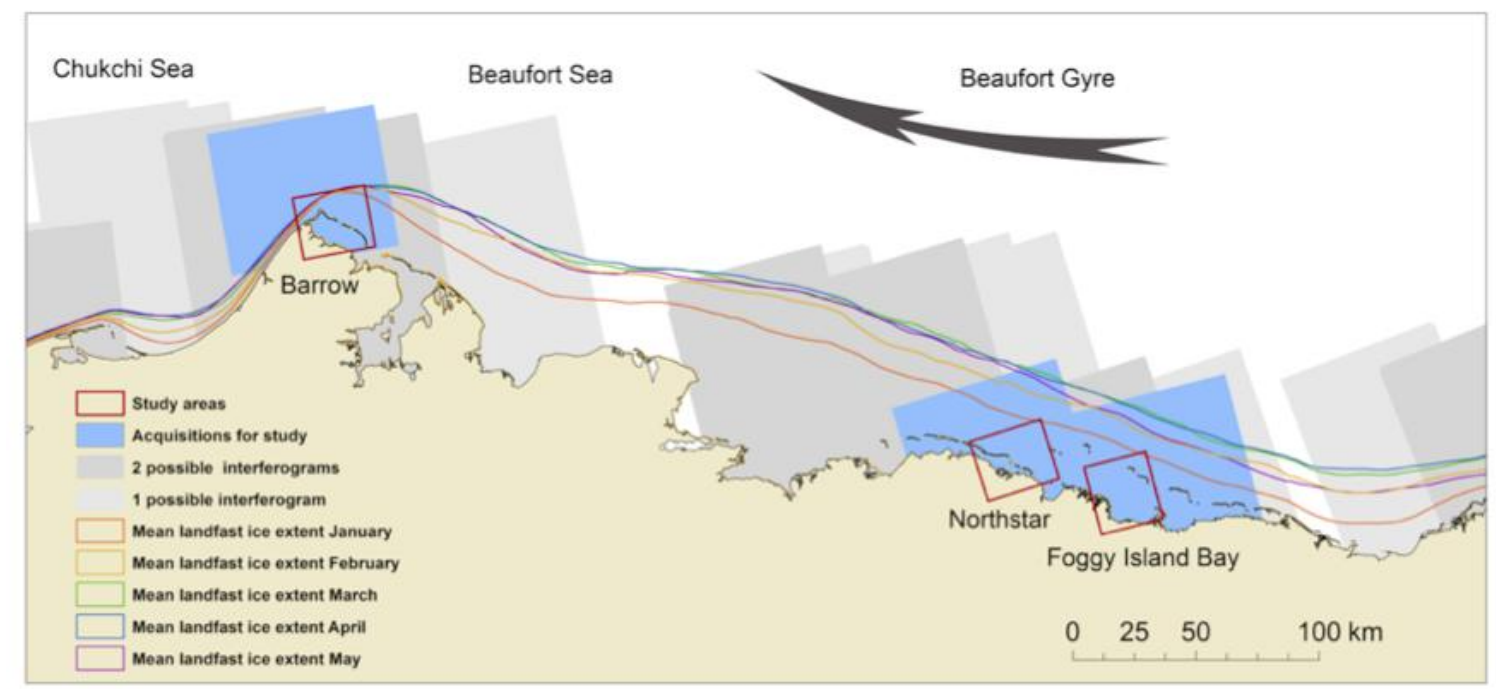

Figure 1: The areas covered by the three interferograms used in this study are shown in blue shading with the specific study areas outlined in red. The regional data availability of ALOS-I PALSAR-I in the middle of the landfast ice season (strictly within JanuaryApril 2010) is shown in gray. The spring monthly mean (1996-2008) landfast sea ice extent is indicated with colored lines [Mahoney et al., 2014].

\section{Table 1}

Orbit and image data for the three interferograms used

\begin{tabular}{lllllll}
\hline Orbit \# & Frame & Dates & $\begin{array}{l}\text { Resolution } \\
(\mathbf{m})\end{array}$ & $\begin{array}{l}\text { Perpendicular } \\
\text { baseline }(\mathbf{m})\end{array}$ & $\begin{array}{l}\text { Temporal } \\
\text { baseline (d) }\end{array}$ & Location \\
\hline 22132 & 1410 & $03 / 21 / 2010$ & Ra: 7.495 & 269 & 46 & Prudhoe Bay \\
22803 & & $05 / 06 / 2010$ & Az: 3.915 & & & \\
\hline 20907 & 1430 & $12 / 27 / 2009$ & Ra: 7.495 & 754 & 46 & Barrow \\
21578 & & $02 / 11 / 2010$ & Az: 3.930 & & 46 & Foggy Island \\
\hline 22278 & 1400 & $03 / 31 / 2010$ & Ra: 7.495 & 325 & & Bay \\
22949 & & $05 / 16 / 2010$ & Az: 4.385 & & & \\
\hline
\end{tabular}


All three acquisitions are covering areas within the landfast sea ice regime (outlined with colored lines in Figure 1). The likelihood of substantial movement (i.e., on the order of a few decimeters to several meters) leading to defects, destabilization or fullscale breakouts, depends on the overall stability of the ice cover. Typically, stability is defined as the ability of shorefast ice to remain immobile and undeformed under the action of atmosphere, ocean, or ice forcing. Depending on the region, ice stability depends on a combination of the anchoring strength imparted by grounded ridges and/or topographic features such as islands or promontories, as well as on ice thickness, structure, and the presence of defects such as pre-existing cracks [Mahoney et al., 2007].

A typical landfast sea ice regime is illustrated in Figure 2 where the stability decreases going from left to right. The most stable ice is the ice frozen to the ground (bottomfast), which is nearly completely stationary. Small-scale non-elastic deformation of lagoon ice or ice sheltered by islands from dynamic forcing is dominated by thermal creep and cracking. Shoreward of grounded ridges, deformation is also governed largely by thermal forcing, but can also be impacted by ice dynamics. Oceanward of any grounding points, the ice is more susceptible to dynamic forcing and the propagating forces from pack ice interaction and is hence less stable (especially younger and thinner ice). Except for the bottomfast ice, even sheltered ice can move several centimeters during a month and therefore exhibits interferometric fringes.

This study focuses on deformation processes in the stable landfast ice zone, which are largely driven by thermal processes (e.g., ice growth, thermal contraction) or moderate dynamic deformation (e.g., wind-generated deformation behind grounding points, internal ice stress generated by pack ice interaction propagating into the stable ice zone) occurring over long time-scales and benefit from a large temporal InSAR baseline. 
By applying a shorter temporal baseline, the methods used in this study can potentially be extended to the pack ice, where the ice is susceptible to dynamic ridging and rafting events and wave propagation [Mahoney et al., 2016], but such analysis is beyond the scope of this study.

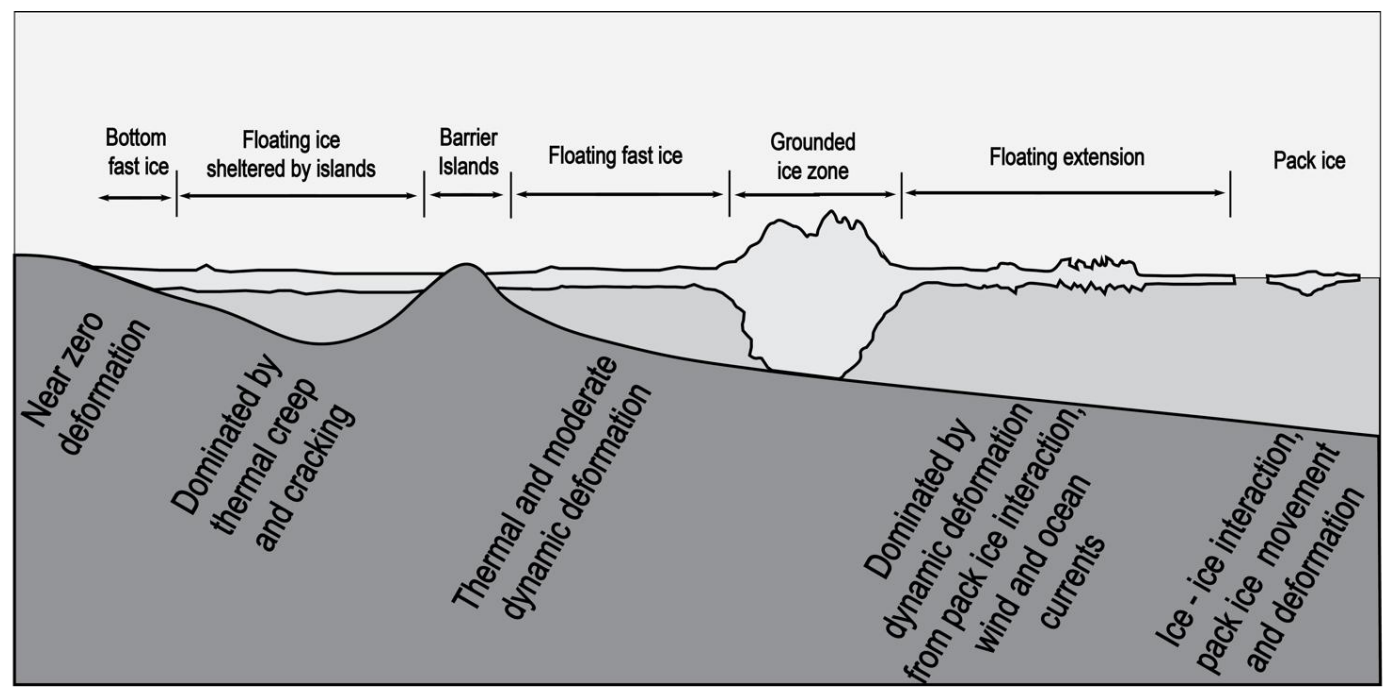

Figure 2: Example of landfast sea ice where different regimes possess different levels of stability.

\subsection{InSAR processing}

Interferograms in this study are constructed using a general processing workflow outlined in Figure 3. The multi-looked interferograms are sampled 2 and 4 pixels in slant range and azimuth respectively. Multi-looking results in pixel spacings of $\sim 15.2 \mathrm{~m}$ and $\sim 12.5 \mathrm{~m}$ in ground range and azimuth, respectively. All acquisitions are from ascending passes. Sea ice interferograms are complicated to interpret due to the many discrete floes that can move in multiple directions. This is also true for landfast ice where the floes are frozen together, but can still behave as mechanically discrete units. The spatial discontinuities 
occurring between acquisitions as well as noise can make phase unwrapping of sea ice difficult [Morris et al., 1999] and we choose to not focus on this processing step since we are mostly interested in the identification of relative displacement in this study. Terrain correction is typically superfluous since the highest ridge features rarely exceed $10 \mathrm{~m}$. For example, for PALSAR to receive a phase signal larger than the expected phase noise from a large ridge, the perpendicular baseline would have to be close to $2 \mathrm{~km}$, far greater than the baselines that are used in this study and are listed in Table 1 (see Section 2.4 for more detailed information regarding topographic influence on fringes).

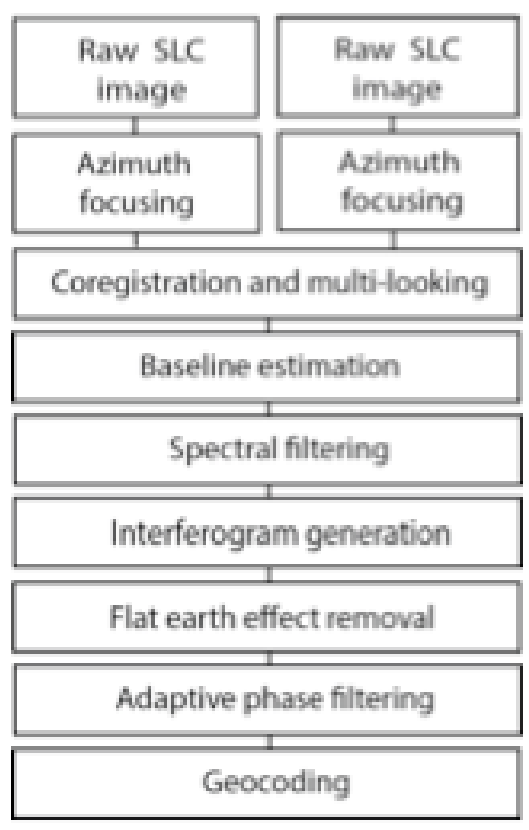

Figure 3: Interferogram workflow outlining steps from two raw single-look complex (SLC) images to a geocoded interferogram.

\subsection{L-band SAR interferometry and coherence over sea ice}

Derivation of image-pair coherence is an integral part of the InSAR processing flow and can provide valuable information about changes on the Earth surface such as those 
related to ice dynamics. An interferogram can be constructed successfully only if scattering between areas in the InSAR partners remains coherent. Complex coherence $|\gamma|$ for two co-registered SAR images $\mathrm{u}_{1}$ and $\mathrm{u}_{2}$ can be estimated from uniform patches, $\mathrm{W}$, around pixels [j,k] using Equation 1.

$$
|\hat{\gamma}[i, k]|=\frac{\left|\sum_{W} u_{1}[i, k] \cdot u_{2}{ }^{*}[i, k]\right|}{\sqrt{\sum_{W}\left|u_{1}[i, k]\right|^{2} \cdot\left|u_{2}{ }^{*}[i, k]\right|^{2}}}
$$

According to Equation (1), the absolute value of the coherence estimate $|\hat{\gamma}[i, k]|$ can range between 0 (complete decorrelation) and 1 (complete coherence). The coherence between images can be reduced by spatial decorrelation due to a large perpendicular baseline causing differences in incidence angle, thermal decorrelation due to low signal to noise ratio, process decorrelation due to errors in image or interferogram processing, or temporal decorrelation due to a change in the scattering medium [Meyer et al., 2011]:

$$
|\hat{\gamma}|=\gamma_{\text {spatial }} \cdot \gamma_{\text {temporal }} \cdot \gamma_{\text {thermal }} \cdot \gamma_{\text {process }}
$$

Temporal coherence decreases as the scattering surfaces either deform or move. From our experience, the most likely contribution to coherence loss in our long-temporal baseline L-band interferograms is related to lateral motion of a sea ice patch. Coherence depends on the magnitude of a deformation shift in relation to the size of the original resolution cell. If uncorrected, this motion displaces scatterers out of a given image resolution cell and introduces new ones, thereby reducing the contribution of overlapping information in the overall scattering response. As both the loss of scatterers and the introduction of new scattering elements contribute to decorrelation, surface motion larger than the size of one resolution cell leads to the complete loss of coherence. The interferometric coherence of ice therefore implies a dislocation of less than one resolution cell between satellite passes (one and a half months in the case of PALSAR) and is thus a more reliable and accurate 
means of identifying landfast ice [Meyer et al., 2011] as compared to methods relying on SAR magnitude data alone to confirm stationarity [Mahoney et al., 2007].

Prior to a study by Meyer et al. [2011], InSAR usage over sea ice had been predominantly limited to C-band $(\lambda=6 \mathrm{~cm})$ data. Meyer et al. showed that the reduced sensitivity of L-band $(\lambda=23 \mathrm{~cm})$ SAR to environmental changes affecting the dielectric properties of sea ice made it suitable for detecting and mapping landfast sea ice. In their study of Alaska landfast ice they employed PALSAR-1 data with a 46-day repeat interval. Processes such as mechanical deformation (e.g. fracturing and tilting) and thermal processes (e.g. brine wicking and drainage, frost flowers and sublimation, recrystallization) will change the scattering properties and reduce coherence, but will rarely result in complete loss of coherence over large areas. The similarity in dielectric properties between air and dry snow results in little backscattering from the snow cover itself. This insensitivity to snow cover is particularly true for L-band with wavelengths substantially larger than snow grains or grain aggregates. Therefore, deposition and wind redistribution of snow will likely not change coherence in winter when the snow is dry. During late spring, snow and ice surface melt, desalination processes, and wet precipitation could result in substantial coherence loss over large areas.

Due to the length of the temporal baseline, we expect the temperature of the ice to change between SAR acquisitions. Based on in-situ data collected at a mass balance station installed in the landfast ice near Barrow [Eicken et al., 2012], we estimate ice surface temperature at Elson Lagoon varied between approximately $-15{ }^{\circ} \mathrm{C}$ in late December to $-10{ }^{\circ} \mathrm{C}$ in mid-March. For the Prudhoe Bay and Foggy Island Bay interferograms, we expect the ice surface temperature varied approximately between -7 ${ }^{\circ} \mathrm{C}$ in late March and $-5{ }^{\circ} \mathrm{C}$ in mid-May. These temperature changes will lead to changes 
in the penetration depth of the microwave energy due to the resulting changes in brine volume. L-band SAR, with a frequency of $1.2 \mathrm{GHz}$, is expected to have a penetration depth in first-year sea ice of between approximately $1 \mathrm{~m}$ and $0.3 \mathrm{~m}$ over this temperature range.

Penetration of the microwave energy into the ice introduces volumetric decorrelation as a result of the different scattering paths caused by differences in incidence angle due to the non-zero perpendicular baseline. Volumetric decorrelation and variation in incidence angle both affect spatial coherence. The relatively large penetration depth of L-band may suggest significant scattering within the ice volume rather than strictly from the surface, which results in enhanced spatial decorrelation.

Thermal coherence depends on the signal-to-noise ratio (SNR) [Weber Hoen and Zebker, 2000]. Over first-year sea ice the SNR of a SAR acquisition largely depends on the morphology of the ice relative to the wavelength. Deformed sea ice, such as pressure ridges and rubble fields, typically has a high backscatter coefficient due to the roughness of the ice surface. However, first-year sea ice that has not undergone mechanical deformation is typically smooth when compared to the large $(0.23 \mathrm{~m})$ L-band wavelength, causing specular reflection and low backscatter under the oblique observation geometries that are typical for SAR. Hence, undeformed first-year sea ice such as that found in lagoons and sheltered embayments will often have a low SNR in L-band SAR data and can be affected by thermal decorrelation [Meyer et al., 2011]. However, most of the sea ice in our study areas shows sufficient backscatter to avoid complete loss of coherence across smooth areas. 


\subsection{Fringe patterns}

The other main source of information in interferometry is the fringe pattern. The interferometric signal is derived from the complex conjugate multiplication of the two image signals:

$$
I=\left|u_{1}\right|\left|u_{2}\right| e^{i\left(\psi_{1}-\psi_{2}\right)}
$$

where $\mathrm{u}_{1}$ and $\mathrm{u}_{2}$ are returned signals from image 1 and 2 with respective phase values $\psi_{1}$ and $\psi_{2}$. The interferogram is the spatial distribution of the calculated phase difference $\Phi:$

$$
\Phi=\arctan \left[\frac{\operatorname{Im}(I)}{\operatorname{Re}(I)}\right]
$$

In order to extract ice motion from interferograms, it is essential to understand the potential causes of phase changes over landfast sea ice. Generally, the phase change has five main contributors [Weber Hoen and Zebker, 2000]:

$$
\Phi=\Phi_{\text {motion }}+\Phi_{\text {topo }}+\Phi_{\text {prop }}+\Phi_{\text {noise }}+\Phi_{\text {error }}
$$

Most of the phase contribution to an interferogram originates in deformation processes caused mainly by lateral or vertical deformation of the ice:

$$
\Phi_{\text {motion }}=\frac{4 \pi}{\lambda} d
$$

where $\mathrm{d}$ is the change in slant range. $\Phi_{\text {motion }}$ is a direct measurement of deformation and lateral displacement with range components of only half the sensor wavelength is sufficient to cause a phase shift of $2 \pi$ (one fringe). It is therefore expected that sea ice interferograms can be useful in studying landfast sea ice dynamics.

With a non-zero perpendicular spatial baseline static, pre-existing topography may also affect $\Phi$. The topographic phase component $\Phi_{\text {topo }}$ can be written as 


$$
\Phi_{\text {topo }}=\frac{4 \pi}{\lambda} \frac{B_{\perp}}{R} \frac{h}{\sin \theta}
$$

where $\mathrm{R}$ is slant range distance to the target, $\lambda$ is the sensor wavelength, $B_{\perp}$ is the perpendicular baseline, $\mathrm{h}$ is the topographic relief of a feature, and $\theta$ is the radar's offnadir look angle. The topographic height difference causing a full phase cycle change between two points in a neighborhood can be described as the ambiguity height, $\mathrm{h}_{\mathrm{a}}$ :

$$
h_{a}=\frac{\lambda R_{s} \sin \theta}{2 B_{\perp}}
$$

[Bamler and Hartl, 1998]. For PALSAR $\left(\lambda=0.25 \mathrm{~m}, \theta=34.3\right.$, and $\left.\mathrm{R}_{\mathrm{s}}=840 \mathrm{~km}\right)$ and $\mathrm{a}$ large $B_{\perp}$ of $1 \mathrm{~km}$, a $2 \pi$ phase change in the interferometric phase will require an altitude difference of $59 \mathrm{~m}$. The $B_{\perp}$ used here are much smaller (Table 1) resulting in even larger heights of ambiguity and, hence, reduced height sensitivity. Ridge heights in landfast sea ice typically do not exceed 10m [Weeks, 2010]. Thus, static topography (i.e. pre-existing ridges) can result in only a minor contribution to the interferometric phase $\Phi$, ruling out topography as a main phase contributor.

$\Phi_{\text {prop }}$ is the phase difference due to a different path lengths caused by spatiotemporal variations of the tropospheric or ionospheric refractive index. $\Phi_{\text {noise }}$ is the random component of the phase that is relevant in areas of low SNR. Orbit errors or coregistration errors can cause significant phase signatures $\Phi_{\text {error }}$ in InSAR data over sea ice. However, the phase contribution from these sources are usually either negligible or can be identified (over areas of flat terrain on land where phase contribution should be close to zero) and corrected [Scharroo and Visser, 1998].

Since the phase contribution to an interferogram mainly originates in deformation processes we will show that interferograms have the potential to reveal the complex small-scale deformation patterns within the landfast sea ice regime. However, 
interpretation of such interferograms is not straightforward since landfast sea ice can undergo multiple modes of 3-dimensional deformation, whereas the interferometric phase measurement only quantifies motion in the slant-range direction between the satellite and the ice surface. To overcome this challenge, we have identified a canonical set of strain processes (e.g., shear, rotation, divergence) that represent the primary modes of sea ice deformation, which can be used to model the interferometric response of sea ice undergoing strain. With these constraints, we can derive most-likely quantifications of the displacement patterns that give rise to the observed interferograms.

\section{Interferometric inverse model to detect and map sea ice displacement}

\subsection{Model structure}

Landfast sea ice can move and deform in several different ways. Hence, our sea ice model needs to encompass a wide range of motion modes in order to enable a realistic physical interpretation of the InSAR data. The canonical motion modes included in our model are (left column in Figure 4): (1) radial divergence as a result of temperature changes causing the landfast ice to compress or expand; (2) rotational motion as a result of shear forces acting on the less laterally constrained parts of the landfast ice far from shore; (3) uni-axial divergence due to external compressional normal forces (such as

onshore wind) causing convergence or tensile forces (such as offshore wind) causing larger displacements where the ice is less constrained; (4) shear motion as a result of shear forcing from less stationary landfast ice or pack ice translating motion into adjacent fast ice; and (5) Surface tilting due to tidal or ocean surge displacement or large-scale buckling of the ice. Note that a solid non-fractured piece of ice moving isotropically in a lateral or vertical direction will result in a uniform phase shift that cannot be observed by 
the interferometric phase (due to the relative nature of InSAR measurements). In our mode, these five canonical displacement modes can be combined to simulate any relative local displacement on the ground.

The model uses known satellite altitude and look angle information to calculate the geometric slant ranges to pixels of an image patch of pre-defined size. The respective phase returns, $\psi$, from the slant ranges, $\mathrm{R}$, are calculated before and after the displacement (Equation 9) according to:

$$
\psi=\frac{-4 \pi}{\lambda} R+\psi_{\text {scatt }}
$$

Interferograms are calculated by multiplying the pre-motion phase pattern with the complex conjugate of the post-motion signal (Equation 3). The model assumes that the scattering properties of the surface remained stable between acquisitions, corresponding to a coherence of 1 . The model also assumes that phase contributions related to topography, atmospheric disturbance, or noise, are negligible. This approach results in a set of simulated interferograms with linear fringes with orientation dependent on a combination of look angle and direction of deformation (right column in Figure 4). If landfast sea ice motion is represented by a combination of different motion modes, the model will only provide the solution of the most dominant of these modes that is driving most of the simulated solution.

As the interferometric phase is only sensitive to the projection of a 3-d motion into the line-of-sight direction, different deformation modes may result in similar phase patterns, leading to potential covariance between model realizations. Uni-axial divergence, shear, and surface tilt are all dependent on the viewing geometry and, hence, must be modeled from multiple directions. The goal was to develop canonical model 
databases with enough viewing angles to resolve local changes in the direction of deformation while still maintaining distinctly different uncorrelated phase structures. Initially 8 angles were simulated, but an increase to 16 angles (every $22.5^{\circ}$ ) provided better results (only the orientation of the axis of uni-axial divergence can be modeled since reversed directions cannot be distinguished).

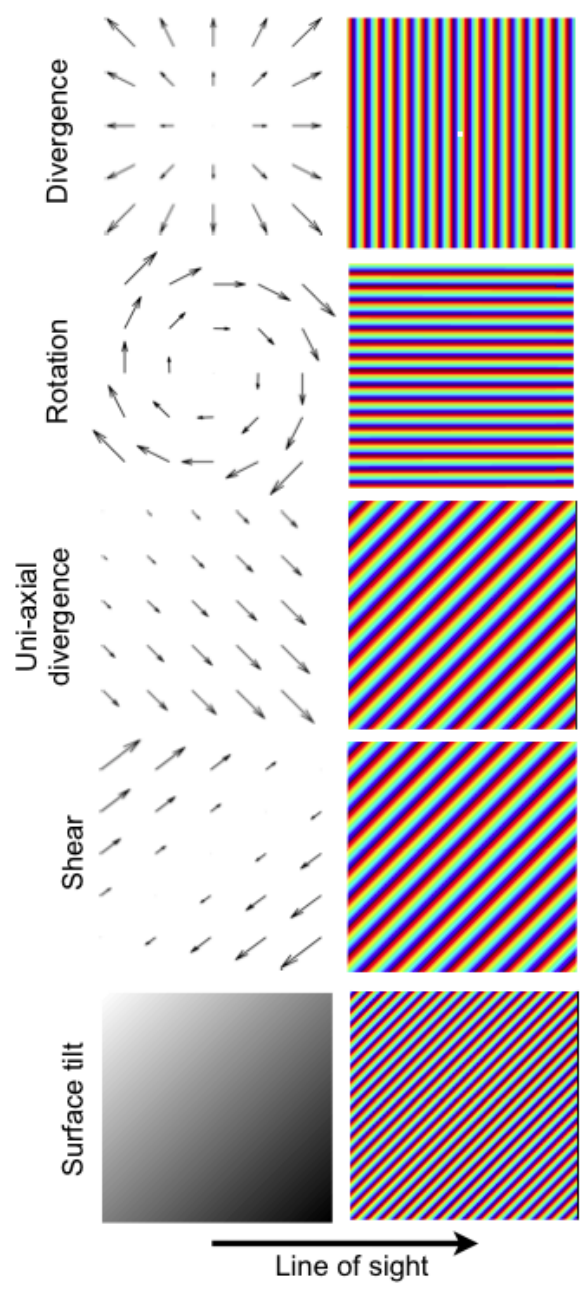


Figure 4: Modes of deformations modeled are displayed in the left column. Modes include divergence, rotation, shear, uni-axial divergence, and surface tilt. These displacements are modeled for 16 look angles varying at 22.5-degree intervals. Rotation and radial convergence are directionally independent. Uni-axial divergence is correlated with reversed directions. Shear and uni-axial divergence in cross-track direction is completely correlated with rotation and radial divergence respectively. Surface tilt is indicated by gray-level shading (brighter shading representing higher elevation). The corresponding modeled interferograms are displayed in the right column.

The result is a total of 44 different modes (including viewing angles) modeled and the correlation between the model databases are calculated in a correlation matrix using Equation 1 (Figure 5). It is apparent that not all model databases display uncorrelated phase structures. Especially, there is high correlation between certain uni-axial divergence and shear modes as well as vertical displacement. Three scenarios exist that are associated with ambiguities, specifically between (1) radial and uni-axial divergence and surface tilt, (2) rotation, shear, and surface tilt, and (3) uni-axial divergence, shear, and surface tilt. 


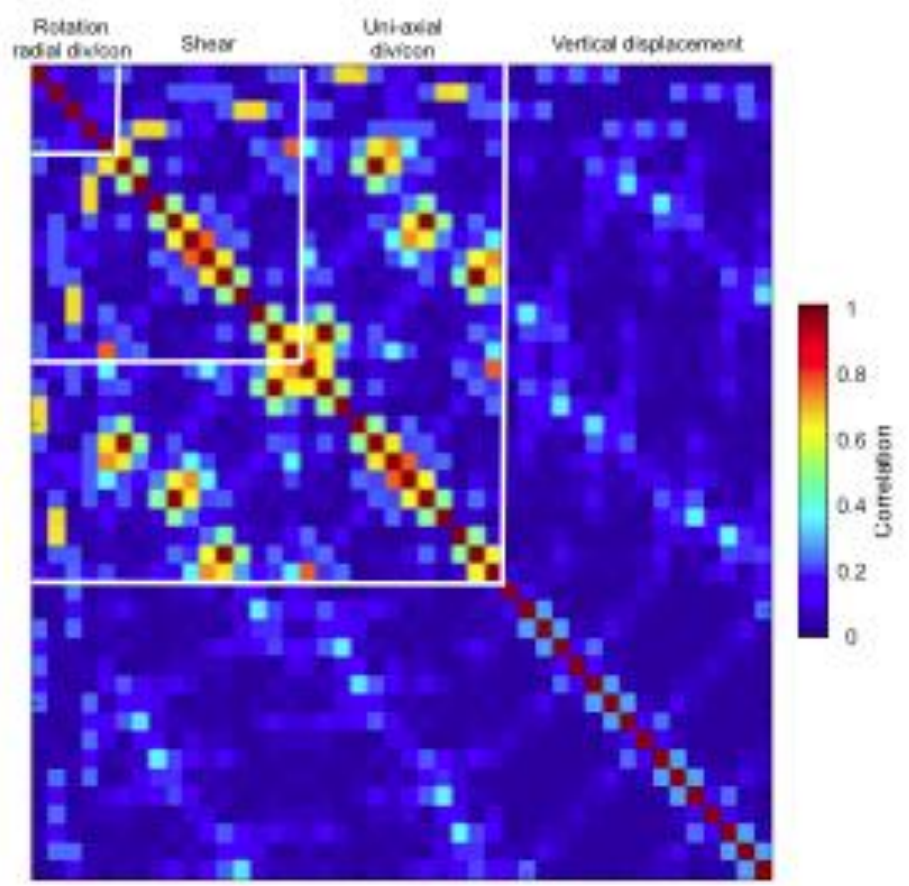

Figure 5: Correlation matrix between the 44 deformation modes (including different angles unless not unique). White lines distinguish between different modes of deformation. Some of the deformation modes produce highly correlated interferograms in particular between shear and uni-axial divergence.

\subsection{Model inversion}

To analyze observed interferograms and determine correct deformation modes we divide each interferogram into square patches whose size matches the size of the model outputs generated at three different resolutions (50x50, 100x100, and 200x200 pixels). The coherence between the data and the modeled patches is calculated for different deformation modes, magnitudes of deformation, and resolution levels and converted to the finest 50x50 grid:

$$
|\hat{\gamma}|_{n, m, r}=\frac{\left|\sum_{W} u_{o} \cdot u_{n, m}{ }^{*}\right|}{\sqrt{\sum_{W}\left|u_{o}\right|^{2} \cdot\left|u_{n, m}\right|^{2}}} n \in\{1 \ldots N\}, m \in\{1 \ldots M\}, r \in\{1 \ldots R\}
$$


$|\hat{\gamma}|_{n, m, r}$ is the coherence between the observed $\left(\mathrm{u}_{\mathrm{o}}\right)$ and modeled $\left(\mathrm{u}_{\mathrm{m}, \mathrm{n}}\right)$ patches for $\mathrm{M}$ deformation modes, $\mathrm{N}$ magnitudes of deformation, and $\mathrm{R}$ number of resolution levels. The coherence determines the consistency in the phase value between measured and modeled patches and ranges from 1 (completely consistent) to 0 meaning the phase values are completely uncorrelated. Coherence therefore is well suited to identify the most likely deformation mode.

Figure 6 shows a map of coherence values between an example patch $u_{o}$ and the $44 \times 20$ model patches $u_{n, m}$. This map illustrates three significant features of a typical model result: (1) Most solutions can be discarded due to low coherence. (2) There is often minor correlation between neighboring cells (as opposed to only one strong peak) due to a slight oversampling, indicating that the correct solution has been identified. (3) The model options with high coherence values are few and not more than three (e.g. certain orientation of shear, uni-axial divergence and surface tilt) are so similar the mode cannot be determined using coherence alone. In many cases this ambiguity between multiple solutions can be addressed through realistic constraints on the resulting strain magnitude or cumulative motion. For example, it is not realistic for surface tilt to continue over great distance without a reversal or discontinuity. 


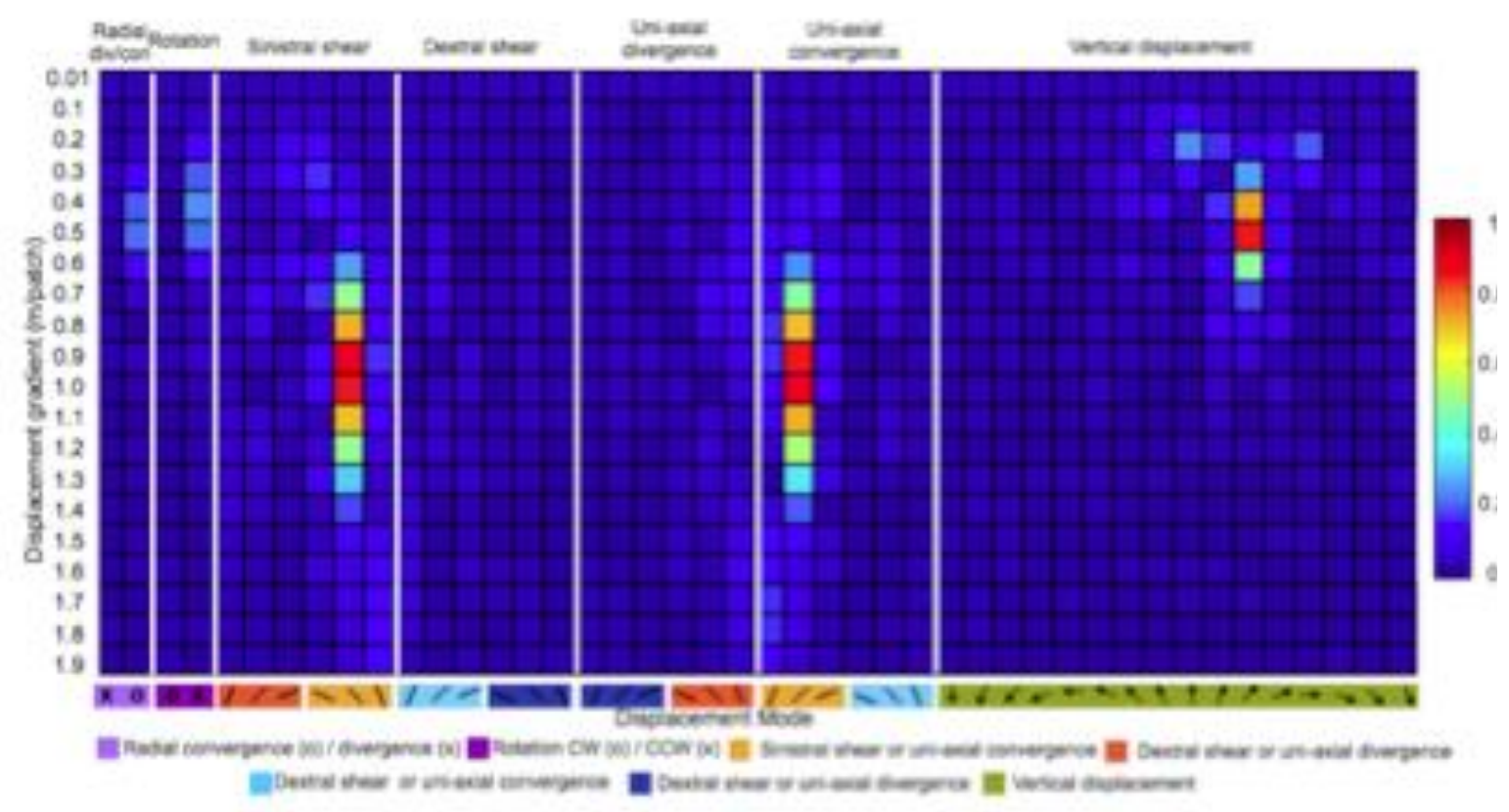

Figure 6: The figure indicates the correlation between an example patch of an observed interferogram and all 44 modeled interferograms (indicated mode above and direction of motion below the correlation map along with the color used to display the particular mode combination) and for 20 displacement gradients. In this case, 45 degree angled sinistral shear with a displacement gradient of $\sim 1 \mathrm{~m}$ (from center to corner of a 50x50pixel patch) is the most likely possibility (due to geophysical constraints - see Section 4.2). Uni-axial convergence and vertical incline towards the upper right corner is also a possibility with almost equal correlation.

The energy $E_{r}$ of the solution for all resolution levels is calculated to determine the confidence that can be placed on the model result. The Energy parameter in Eq. (11) is convenient because it conveys in one number whether the model has found a set of distinct solutions such as in Figure 6. The energy is calculated in the original grid and based on the ratio of the mean coherence in the entire map (Figure 6) over a Gaussian 
approximation, $|\hat{\gamma}|^{\prime}$, of the largest peak integrated within one standard deviation of the peak amplitude value:

$$
E_{r}=1-\frac{\overline{|\hat{\gamma}|_{n, m, r}}}{\int_{n=-\sigma}^{n=\sigma}|\hat{\gamma}|_{n, m^{\prime}, r^{\prime}}} \quad r \in\{1 \ldots R\}
$$

$E_{r}$ will range between 1 for a strong (and unique) peak and 0 for the case where no peak could be identified at all. At the end of the process, the lower resolution peak estimates $E_{100}$ and $E_{200}$ are resampled to the denser $E_{50}$ grid and the final combined deformation mode $\mathrm{m}$ ' is found belonging to the highest coherence of the resolution possessing the highest energy:

$$
|\hat{\gamma}|_{n^{\prime}, m^{\prime}, r^{\prime}}=\max _{n, m}|\hat{\gamma}|_{n, m, r^{\prime}} \text { where } E_{r^{\prime}}=\max _{r} E_{r}
$$

\subsection{Model ambiguities and constraints}

Ambiguities (see Figure 6) between modes of displacement frequently occur between vertical tilt and the lateral displacement modes and the model results may favor one or the other solution based on slight differences in the observed fringe pattern, sometimes resulting in motion mode estimates that do not make physical sense. Often the interferogram itself provides guidance on whether fringes are due to vertical or horizontal displacements. For example, while surface tilt (vertical motion) might result in a fringe pattern that resembles that of shear or rotation (horizontal motion) for a single tile, it is not realistic to expect surface tilt to remain constant over significant distances since the cumulative vertical displacement would become unrealistically large. At some point the tilt must reverse, which will lead to concentric elliptical fringe patterns in the interferogram. Therefore, we decided to add region-specific conditions to our geophysical model. Where interferograms lack significant elliptical fringe patterns, the model is 
conditioned to only simulate horizontal motion (Section 4.1, and 4.2). However, in areas where the interferogram indicates significant vertical motion the model is constrained to only simulate vertical deformation (Section 4.3) to resolve the vertical deformation of these areas specifically.

Ambiguities between shear and uni-axial divergence (both horizontal modes) can often be visually eliminated based on a combination of geographical constraints such as coastline orientation, predominant forcing patterns, and speckle tracking of less constrained landfast ice. Ambiguities can also occur (1) when the ice experiences multiple different modes of deformation within a modeled patch, (2) if there is sufficient coherence loss in the interferogram, or (3) if the deformation is so low that there is not sufficient phase gradient within a model patch. The three different resolutions were chosen based on experimentation to minimize these ambiguities. The high resolution is effective in capturing small areas with uniform deformation, but is limited by the need to achieve sufficient phase gradient to minimize ambiguities and the influence of noise. The low resolution is chosen to be able to capture most of the larger features apparent in the interferograms with high energy and provide results of sufficient phase gradient during slow deformation and in areas of low interferogram coherence, but is limited by often multiple different deformation modes within a patch.

\section{Model results and interpretation}

\subsection{Validating the model over Elson Lagoon, Alaska}

This section aims to validate the model by first explaining the model results before analyzing whether the results are geophysically plausible. The area to validate the model is Elson Lagoon close to Barrow, Alaska. 
This location features first-year sea ice varying in roughness from smooth ice inside the lagoon to heavily deformed rubble and ridge fields outside the lagoon. Based on nearby sea ice mass balance research site data the ice thickness can be estimated to have grown from roughly $0.5 \mathrm{~m}$ to $1.0 \mathrm{~m}$ in the time between acquisitions. This area was chosen as a model test site primarily for two reasons. First, the University of Alaska Geophysical Institute sea ice research group and the Seasonal Ice Zone Observing Network (SIZONet) have focused their fieldwork on Barrow and the surrounding areas for more than a decade, including annual studies of sea ice thermal and dynamic development, large-scale morphology and microstructure [Druckenmiller et al., 2009]. Our group therefore has knowledge of the ice environment in Elson Lagoon as well as real-time thermal and mass balance data collected nearby, which helps constrain physical properties of the landfast ice and greatly benefits the analysis and evaluation of the model. Second, the barrier islands semi-enclosing the lagoon reduce the number of deformation modes and the severity of deformation, and hence narrow down the expected solutions of the model.

An amplitude image from 27 Dec. 2009 is examined (Figure 7a) followed by a series of three consecutive interferograms from 27 Dec 2009 - 14 May 2010 (Figure 7bd). The ice in the lagoon exhibits low backscatter characteristic of smooth first-year ice that dominates the lagoon (Figure 7a). A few linear, high backscatter features most likely representing low-elevation pressure ridges and rough ice formed during the first few weeks of ice growth can also be identified (most notable one marked with an arrow in Figure 7a).

The interferograms (Figure 7b-d) exhibit fringes both inside and outside the lagoon, but lose coherence a few kilometers off shore from the barrier islands. The 
interferogram in Figure 7c exhibits partial coherence loss inside and outside the lagoon possibly in part due to ice growth extending the ice-water interface beyond the penetration depth of the radar leading to an altered backscatter signal. The density of fringes is an indication of the rate of deformation with a higher fringe density indicating a higher rate of deformation. The thicker the ice gets the less freely the ice can deform due to its increased strength. Early in the winter (Figure 7b), the landfast ice is still fairly thin explaining the high fringe density. Outside the lagoon, the landfast ice furthest offshore (that still exhibits coherence) deforms more rapidly due to the reduced lateral constraints. Later in the season (Figure 7c) the predominant fringe patterns remain mostly consistent but with reduced fringe density due to the increased stability resulting from thicker ice. By spring (Figure 7d) the lagoon ice has stabilized to the point where lateral deformation is almost non-existent. Even outside of the lagoon, the ice exhibits substantially reduced motion. The continued increase in stability within the lagoon is due to ice growth, while outside the lagoon can also be attributed in large part to the formation of grounded ridges sheltering the landfast ice from further deformation.

Particularly early in the season (Figure 7b), the fringe overall pattern shows localized distinctively different regions of internally uniform deformation behavior. The sharp boundaries between these regions (indicated by discontinuous fringes) likely represent a dislocation allowing discontinuous ice to deform more independently. Similar thermally induced dislocations have been observed in Elson Lagoon as cracks extending for several kilometers with a width of less than half a meter. The cracks are associated with only small $\mathrm{cm}$-scale change in elevation as well as moderate altered roughness making them difficult to recognize with L-band SAR, but can be identified in X-band amplitude images. As the season progresses it is clear that the number of active 
dislocation cracks declines (due to fewer severe cold spells fostering thermal cracks and increasing ice thickness reducing overall stress) while the general deformation patterns persist under increasingly stabilized ice conditions. The interferograms provide valuable information indicating the difference in deformation gradient across these lines.

a) Amplitude image 27 Dec. 2009

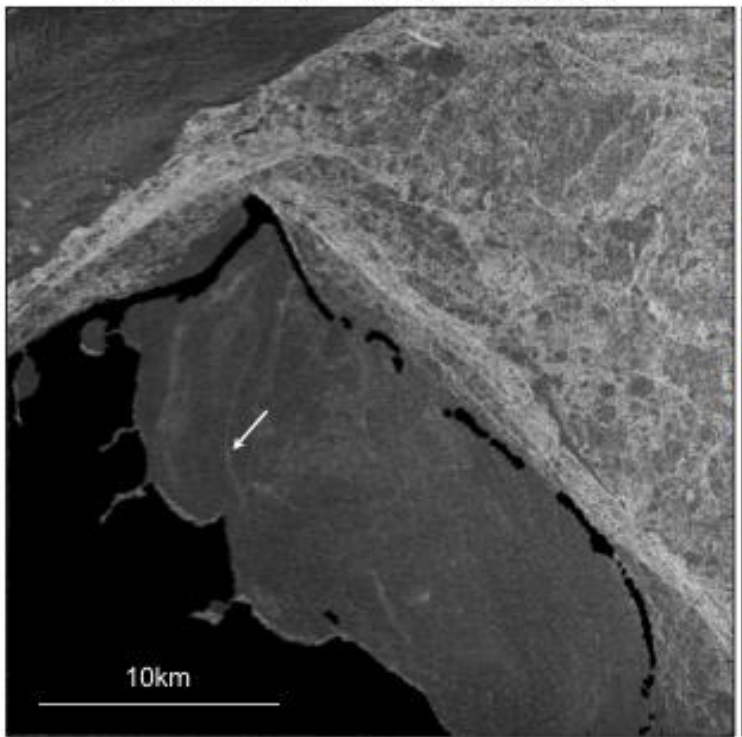

c) Interferogram 11 Feb. 2010 - 29 Mar. 2010

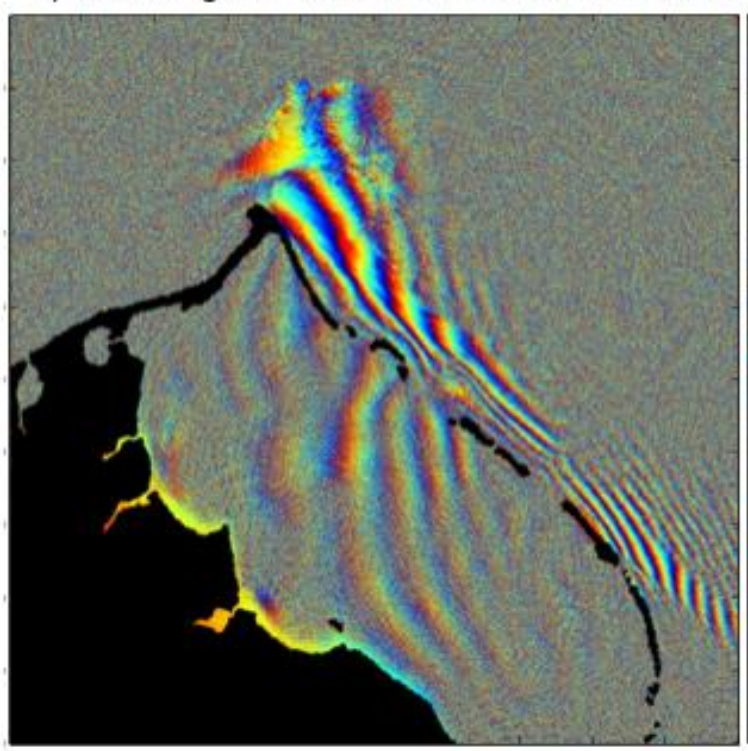

b) Interferogram 27 Dec. 2009 - 11 Feb. 2010

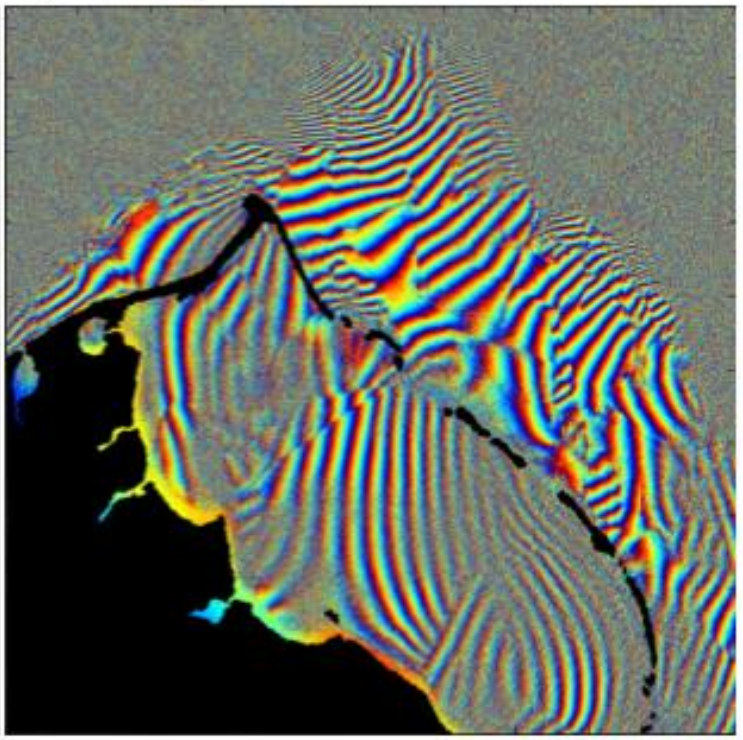

d) Interferogram 29 Mar. 2010 - 14 May 2010

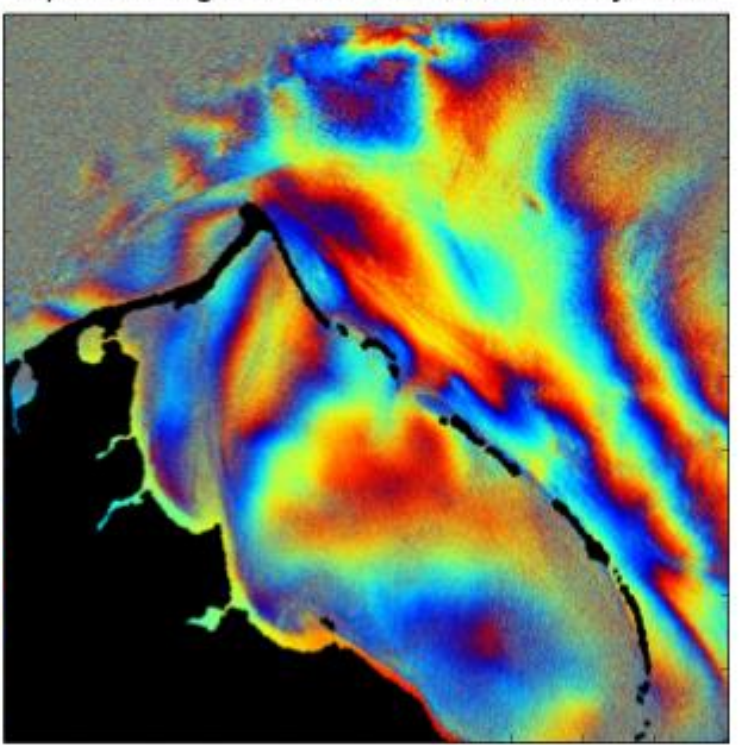

Figure 7: (a) Amplitude image over Elson Lagoon, Alaska (27 Dec 2009). The land is 
masked out in black. (b-d) Interferograms created from the consecutive acquisition pairs identified in the image labels.

a) Displacement mode

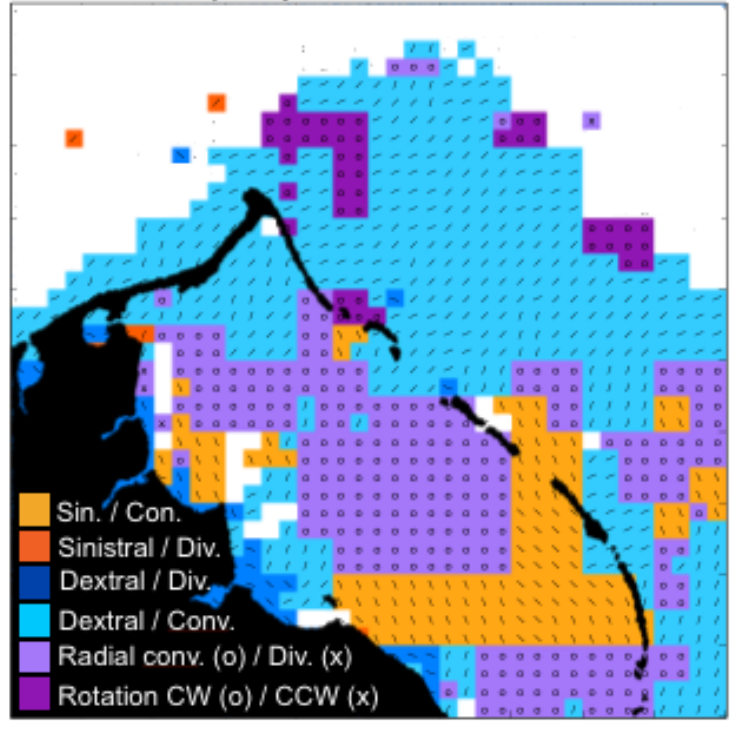

b) Energy

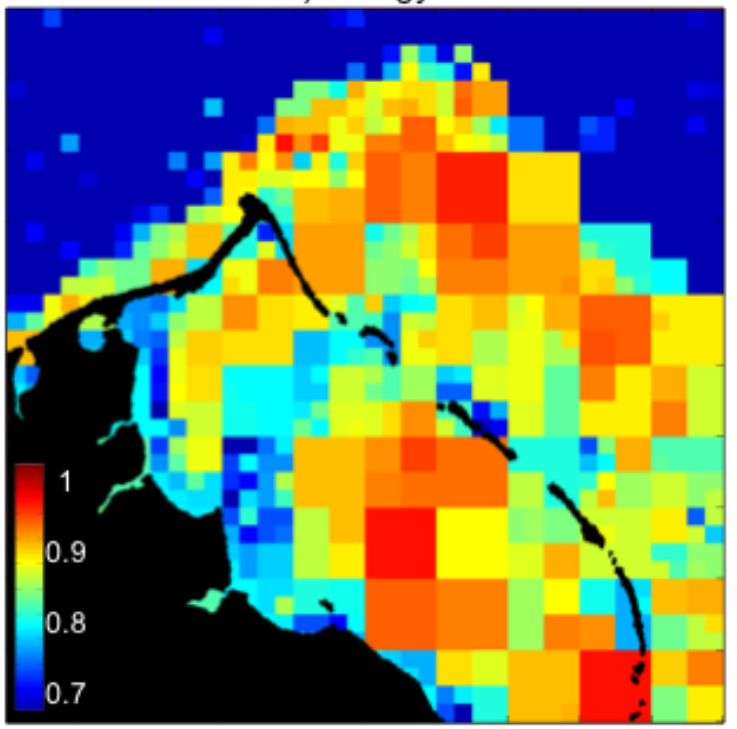

Figure 8: (a) The model results display deformation mode with colors corresponding to the specific combinations of deformation mode. Light and dark purple correspond to modes that are independent of the viewing angle, including radial divergence and rotation, respectively. Yellow and orange colors indicate left-handed (sinistral) shear and uni-axial convergence or divergence, respectively. Blue and cyan indicate right-handed (dextral) shear and uni-axial divergence or convergence, respectively. The lines indicate lines of equal deformation (parallel to shear and perpendicular to uni-axial divergence) and " $\mathrm{x}$ " and "o" correspond to divergence / counter clockwise rotation and convergence / 
clockwise rotation respectively. (b) Energy of the model results indicating certainty of the model (see Section 3.2 for details). White colors in figure c correspond to where energy did not exceed 0.7 .

The model is applied to the first interferogram (27 Dec 2009 - 11 Feb 2010) when the lagoon is most dynamic and was confined to using horizontal modes of displacement only (top four modes in Figure 4). Constraining model output to lateral motion is justified due to the lack of closed circular features in the interferogram often indicating buckling (See Section 3.3). The result of the model inversion is displayed in Figure 8a, in which grid cell colors correspond to at most two possible deformation modes.

The plot of energy (Figure 8b; Equation 11) is a measure of model output confidence. Overall, the model results indicate that the mode of ice deformation was homogenous over length scales of up to $10 \mathrm{~km}$, as illustrated by the spatial extent of contiguous cells of the same color. The spatial homogeneity of model solutions is a good validation of the model in of itself and indicates that the model can delineate smoothly varying physical processes. The majority of Elson Lagoon is dominated by radial convergence (light purple) as indicated by the "o" symbols. The ice surrounding the central convergence in the lagoon is dominated by either sinistral (left-handed) shear (yellow) and dextral (right-handed) shear (cyan) parallel to the coastline or uni-axial convergence perpendicular to the coastline. The ice seaward of the barrier islands is almost exclusively dominated by either dextral (right-handed) shear perpendicular to the coastline or uni-axial convergence (cyan) with motion direction parallel to the coastline.

The lagoon is semi-enclosed, reducing the amount of stress from pack ice interaction. Hence ice deformation in the lagoon is expected to be primarily due to 
thermal stresses during this 46-day repeat pass period. The discontinuities between regions of consistent fringe patterns are likely to have experienced thermal stresses exceeding tensional yield stress resulting in formation of thermal cracks. On each side of the central radial convergence zone the model suggests either shear deformation parallel or uni-axial convergence perpendicular to the coastline. Here, uni-axial convergence is the most likely scenario where the uni-axial convergence region is separated from the radial convergence zone through discontinuities apparent in Figure $7 \mathrm{~b}$ (most likely thermal cracks which have been observed in the area during previous field seasons). Shear deformation - in particular un-interrupted sinistral shear extending from one side of the lagoon to the other (Figure 8a) - is a less plausible explanation of the observed interferometric patterns. In contrast, the model solutions corresponding to radial and uniaxial convergence are geophysically plausible for the lagoon site in mid-winter.

Outside of the lagoon, the model indicates possible uni-axial convergence parallel to the barrier islands, which would be consistent with westward displacement of offshore pack ice translating forces onto the landfast ice kept in place by the barrier islands and Point Barrow. The other model solution corresponds to dextral shear perpendicular to the barrier islands, which is geophysically less plausible in the absence of associated nearcoast convergence.

The results obtained in the Elson Lagoon area were consistent with local knowledge of the region and lend confidence to the performance of the model. The goal of this model evaluation was to test the model and learn how to interpret results so that the model can be utilized without further prior local knowledge of the individual location we utilize the model. The next sections will explore model output in a region with significant interaction of landfast ice with offshore pack ice and where the approach 
outlined above can address stakeholder information needs. For instance, how does the landfast ice deform around the Northstar Island ice road and drilling operation in the Beaufort Sea and what is the driver of the observed deformation (Section 4.2)? Also, what is the dominant deformation around the proposed Liberty prospect where ice motion is currently a concern for planned drilling activities (Section 4.3)?

\subsection{Model results near Northstar Island, Prudhoe Bay, Alaska}

Northstar Island [Krieger et al., 2003] is a man-made gravel island located near the center of the Northstar oil and gas prospect in the Beaufort Sea near Prudhoe Bay (circled in Figure 9a). The island is connected to land with an ice road during winter months (arrow in Figure 9a) and transportation of supplies using heavy trucks and reinforcement of the ice road using construction machinery are both critically dependent on the stability of the ice [Bashaw et al., 2013; Potter et al., 1981]. The sea ice around Northstar is first-year sea ice that is generally smooth shoreward of barrier islands and shoreward of Northstar Island, with certain areas prone to cracking and ridging. Oceanward of Northstar, the ice is more heavily deformed as seen in the amplitude image. Based on airborne EM surveys, the landfast sea ice conditions in the western Beaufort Sea are comparable to Barrow (Mahoney, unpublished data), hence we can estimate that ice thickness grows from roughly $1.1 \mathrm{~m}$ to $1.3 \mathrm{~m}$ between acquisitions. 
a) Amplitude image

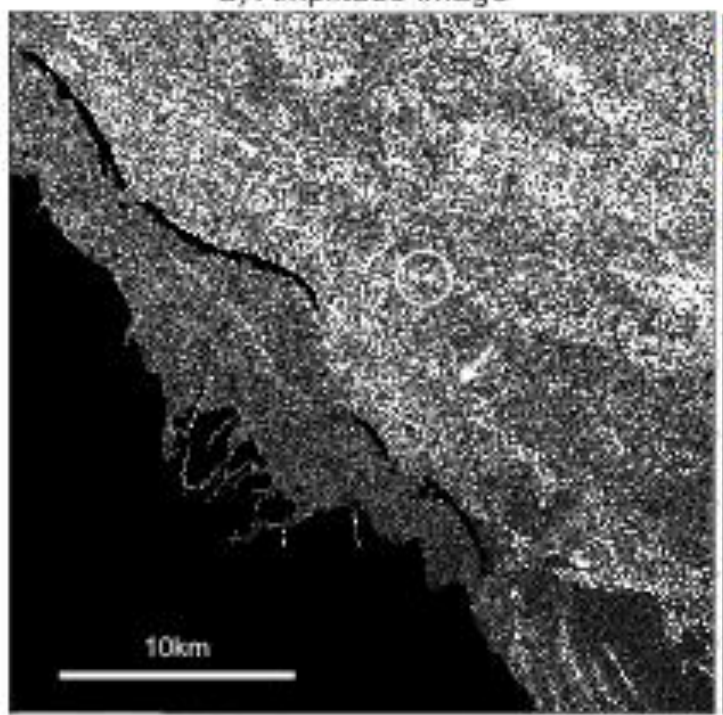

c) Displacement mode

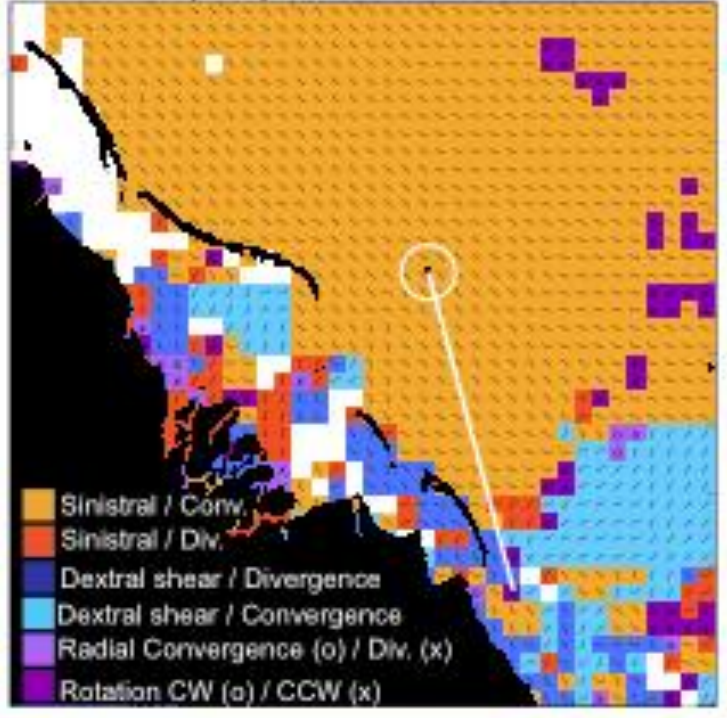

b) Interferogram

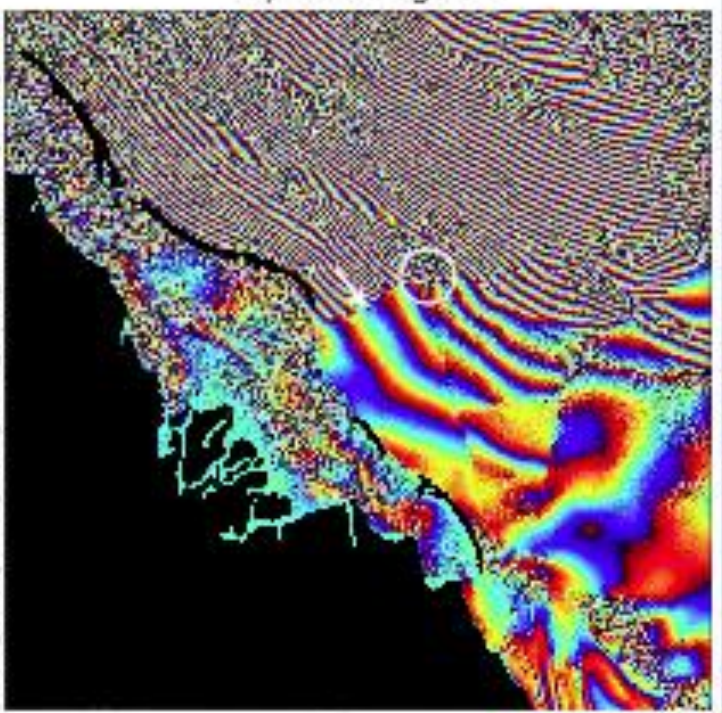

d) Energy

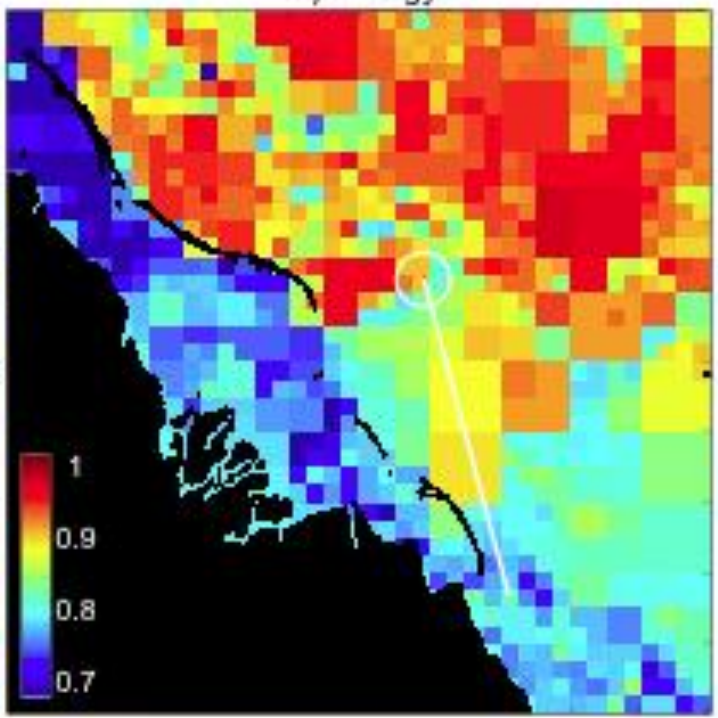

Figure 9: (a) Amplitude image for the Northstar Island (circled) and Prudhoe Bay region, Alaska (21 Mar 2010) (arrow pointing to the ice road connecting the island to the mainland) and (b) the interferogram created from this and the following acquisition (6 May 2010) (arrow pointing to boundary between high and low fringe density at Northstar Island). (c) The model results display deformation mode with colors corresponding to the specific combination of deformation modes. The lines indicate lines of equal deformation (parallel to shear and perpendicular to uni-axial divergence) and " $\mathrm{x}$ " and "o" correspond 
to divergence / counter clockwise rotation and convergence / clockwise rotation respectively. (d) Energy of the model results indicating certainty of the model (see Section 3.2 for details). White colors in figure c correspond to where energy did not exceed 0.7 .

The interferogram produced from an image pair for March 21 and May 6, 2010 is chosen due to the stark contrast between the higher fringe density oceanward and lower fringe density shoreward of Northstar Island, suggesting that potential anchor support by the island contributes to the local stabilization of shorefast ice (arrow in Figure 9b). The ice road is associated with a noteworthy displacement of interferogram fringes suggesting that road construction or maintenance impacts the dynamics of the underlying ice. The inverse displacement model results (Figure 9c) indicate large areas of either uni-axial convergence perpendicular to the coastline or sinistral shear deformation with northwesterly ice movement increasing with distance to the coast (Figure 9c).

The shear field is consistent with an ocean current and pack ice interaction parallel to the coast from east to west. This pattern is expected due to the consistency with the general velocity field of the Beaufort Gyre - a persistent wind driven ocean current in the Arctic Ocean illustrated in Figure 1 - and is the most plausible model solution.

For most areas, model solution energy is high as a proxy for model confidence (Figure 9d). The energy is larger northeast of Northstar due to a combination of coherent signal and homogenous fringe orientation and fringe spacing enabling the model to more accurately identify the most plausible solution. Due to low coherence inside the barrier islands, model output confidence is not high enough to be included in the analysis. 
As an independent verification and to potentially narrow down solutions, we also calculated landfast ice displacements through non-coherent cross correlation, also known as speckle tracking (Figure 10). This technique determines sub-pixel surface displacements without considering phase information [Bamler and Eineder, 2005], requires large displacements and is not nearly as accurate as interferometric approaches. Cross correlation displays absolute movement and is therefore more sensitive to coregistration and orbit errors than the relative motion from interferometry. Nevertheless, the speckle tracking validates the sinistral shear model result displaying an increase in displacement ocean-ward of Northstar Island with similar orientation as indicated by the model (Figure 9).

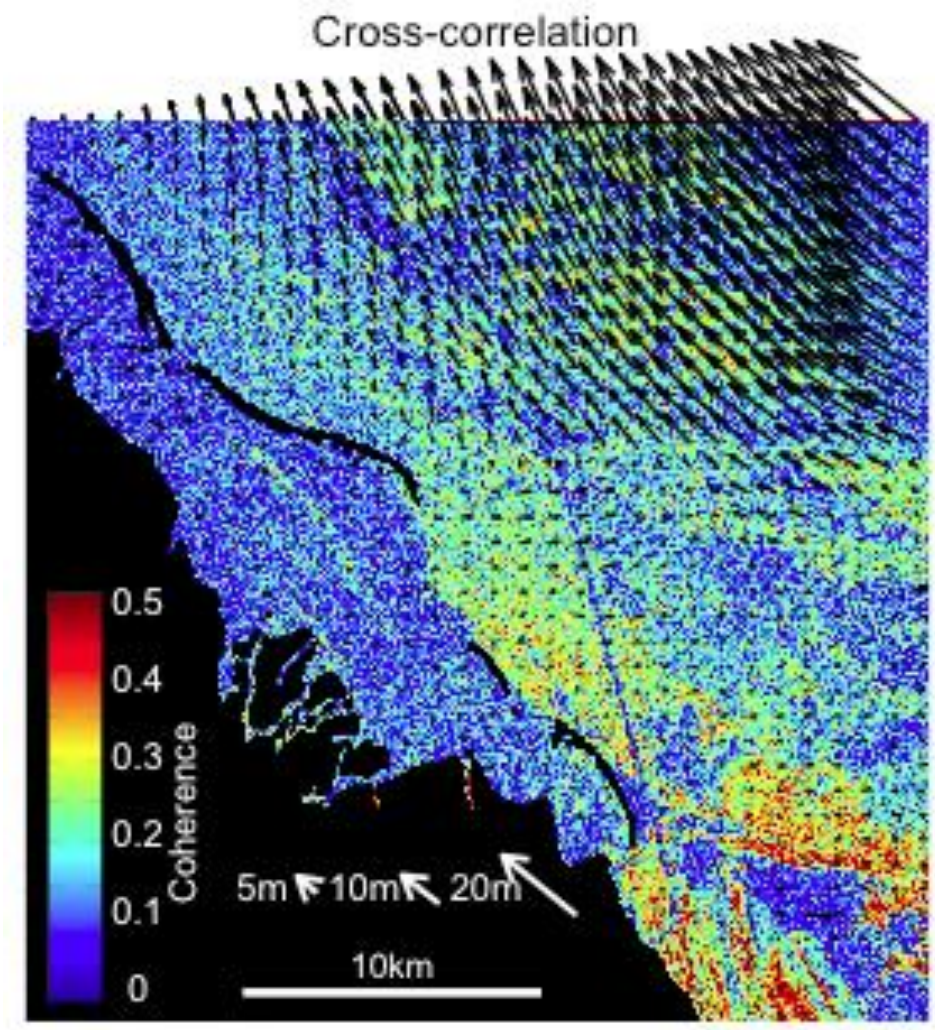

Figure 10: Incoherent cross-correlation displacement vectors superimposed on the interferogram coherence over Northstar (21 Mar 2010 - 6 May 2010). The ice road is 
apparent as an area of reduced coherence due to ongoing road construction (snow removal and thickening of the ice through pumping of water onto the ice surface). The vectors indicate a large area of uniform left-handed (sinistral) shear motion.

\subsection{Assessing vertical displacement at Foggy Island Bay, Alaska}

So far we have used the model to derive horizontal motion only and excluded vertical displacements. It is important to identify and model displacement in the vertical direction that is substantial enough to invalidate a strict lateral solution. A vertical ice displacement of $d_{v}$ will produce an interferometric phase:

$$
\Phi=\frac{4 \pi}{\lambda} d_{v} \sin \theta
$$

A region with a phase ramp will therefore correspond to a tilted surface, such as might be caused by depression under a heavy load, buckling under lateral stress or doming due to excess pressure under the ice between confining areas of bottomfast ice. In most cases, coherent ice surfaces cannot support significant vertical displacements across multiple model tiles (since non-realistic vertical displacement would be reached) and so any surface tilt as well as the fringes will have to reverse within relatively few fringes. This will result in elliptical features in the interferogram. A plausible maximum vertical displacement of $2 \mathrm{~m}$ (1m of freeboard and $1 \mathrm{~m}$ sea level displacement) would result in 9 circular fringes. An example is the interferogram over Foggy Island Bay, where vertical displacement has to be considered. This locale is of interest because it is the target of planned exploration drilling (Liberty prospect) associated with the need for (temporary) infrastructure development that utilizes the ice as a platform and may be impacted negatively by movement or loss of stability of the shorefast ice [Hilcorp, 2015]. 
According to British Petroleum, the operator of Liberty until 2014, ice movement was noted during the 2013 Liberty Geotechnical Program [BP, 2013], creating the need for GPS deployment to track ice motion at specific points, an approach that has proven useful, though with limitations [Tucker et al., 1980; Weeks, 1977].

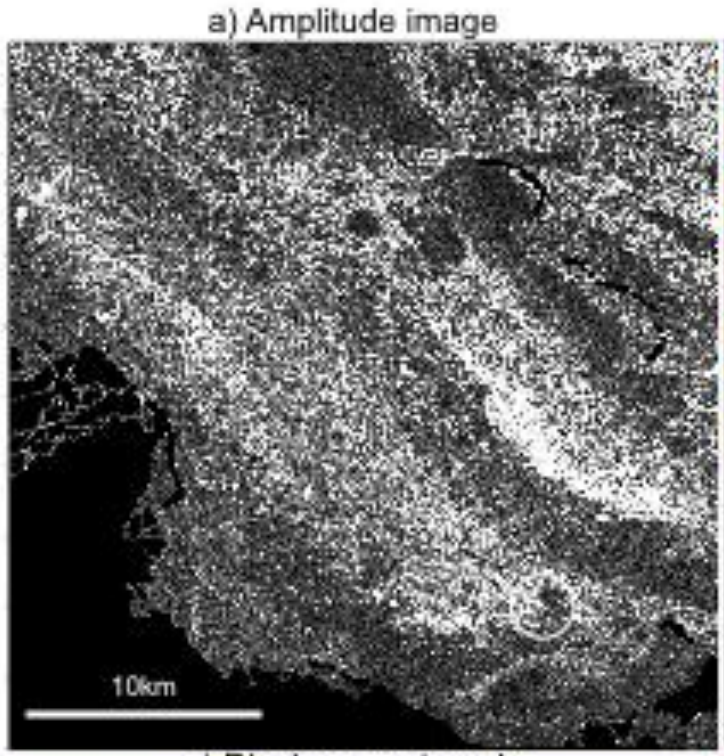

c) Displacement mode

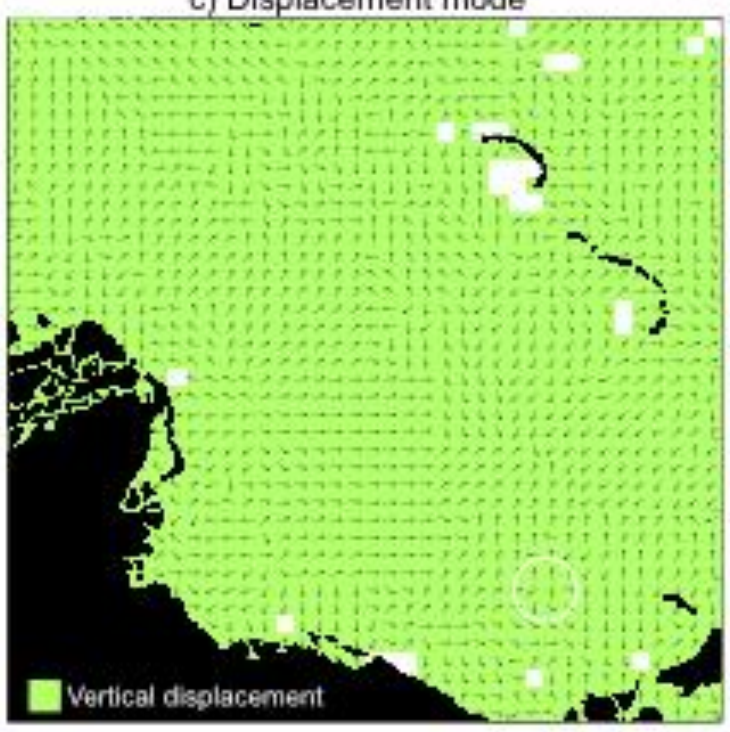

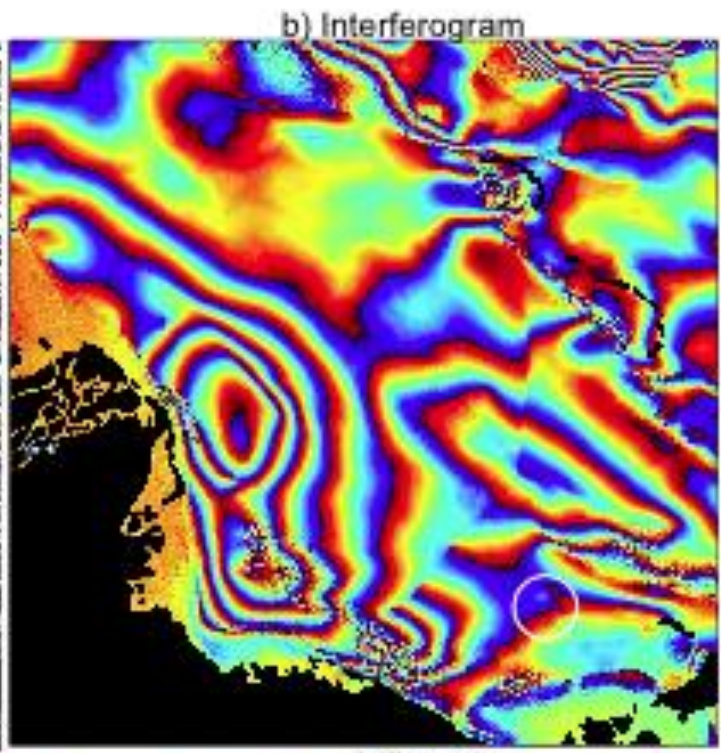

d) Energy

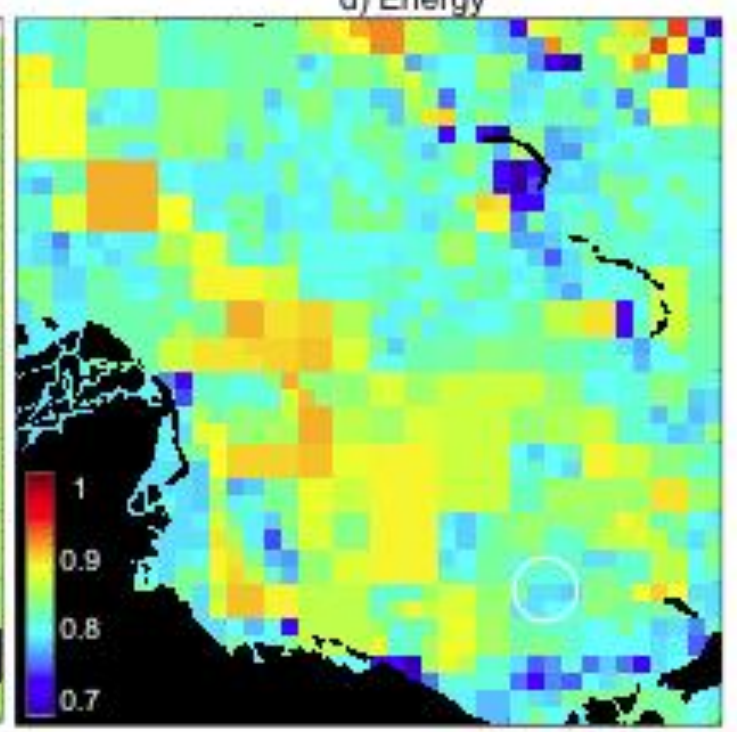

Figure 11: (a) Amplitude image over Foggy Island Bay and the Liberty prospect (Liberty is roughly indicated with a circle and Endicott is marked with an arrow) near Prudhoe 
Bay, Alaska (3/31/2010) and (b) the interferogram created from this and the following acquisition (5/16/2010). (c) The model results display direction of surface tilt with arrows pointing towards higher elevation. The model is set to only match vertical displacement. (d) Energy of the model results. White cells in Figure 11c correspond to an energy of 0.7 or less.

Foggy Island Bay is located about $25 \mathrm{~km}$ east of Prudhoe Bay and east of Endicott Island. The near-shore landfast ice consists of relatively level first-year sea ice with more heavily deformed ice further offshore in areas where the coastal morphology is not offering protection from pack ice interactions from the Beaufort Gyre (can be seen from Figure 11a). The interferogram is formed late in the season (ice thickness estimated to grow from roughly $1.2 \mathrm{~m}$ to $1.4 \mathrm{~m}$ between acquisitions) and was chosen due to the noteworthy circular features (Figure 11b) that we interpret as regions of vertical displacement. In the westernmost part of the bay is a depression of about four fringes, which corresponds to a peak vertical displacement of about $90 \mathrm{~cm}$. East of this depression (north of Liberty) is a ridge of about 2 fringes indicating near half-meter displacement.

If running the model with both horizontal and vertical modes, some of the tiles as part of the circular features are derived as uni-axial divergence perpendicular to the center of the circular features (not shown). However, with no discontinuities and likely homogeneous forcing of the ice it is unlikely that the features correspond to uni-axial divergence. The two main circular features account for most of the significant deformation in the interferogram, hence the model can easily be stabilized by running only vertical displacements. However, if there were other non-circular features that needed to be captured, the model would have to be run in horizontal mode to understand 
the remaining features. The vertical result is plotted in Figure 11c as arrows pointing towards higher ground. The model correctly identifies tilting towards the direction of the center on all sides of the depression and ridge. The energy (Figure 11d) is reduced as compared to the lateral results partially due to low fringe density and higher mean coherence (Equation 11) when considering fewer deformation modes.

\section{Discussion}

The inverse model has been shown to identify different modes and gradients of deformation with reasonable confidence, consistent with recurring local-scale ice dynamics patterns and quantitative information obtained from cross correlation analysis of SAR amplitude images. The most important model uncertainty is associated with picking the best solution in case of ambiguities. These ambiguities are likely inherent in the InSAR method based on the one-dimensional nature of the phase values. For other media experiencing more consistent deformation (e.g., glaciers) some ambiguities can be resolved using both ascending and descending passes acquiring model results from different angles [Lang 2002]. This can be achieved since (1) radial divergence and rotation is independent of look direction, hence fringe orientation will change dependent of the viewing geometry, (2) fringes as a result of shear displacement will remain constant regardless of viewing geometry, and (3) fringes as a result of uni-axial divergence will either remain constant or exhibit reversed phase gradient depending on viewing geometry. Acquiring two interferograms with separate viewing geometry is rarely possible over sea ice since both interferograms would have to be acquired close in time due to the frequently changing sea ice dynamics. However, even with only one interferogram, wrong solutions can often be ruled out or identified as unlikely based on 
surrounding ice displacement, a restricting coastline, cross correlation validation, or nonisotropic solution. If obtaining shorter temporal baseline pairs, such as rapid repeat pursuit mode interferometry using TanDEM-X [e.g., Mahoney et al., 2016], it may be possible to utilize this model approach on pack ice with little to no access to prior local knowledge about the current ice dynamics. The model solutions would in such case be constrained either using large-scale velocity fields such as derived from Special Sensor Microwave Imager (SSMI) or directly from the SAR dataset through cross correlation analysis as described in Section 4.2.

As discussed in Section 2.4, interferometric fringes over landfast sea ice will be caused almost exclusively by small-scale deformation of the sea ice. However, it is important to consider the impact of tidal action or the effect of an ocean surge on this analysis (not leading to permanent vertical change). In the Beaufort Sea the tidal range is about $20 \mathrm{~cm}$ (roughly one fringe using Equation 13 ), but can be much larger $(\sim 1 \mathrm{~m})$ in other areas such as Norton Sound [Huang et al., 2011]. In the Beaufort Sea, larger sea level changes (up to $2.5 \mathrm{~m}$ [Weingartner et al., 2009]) can occur due to altered surface pressure, ocean currents, and gravity waves, but are uncommon. Over an area of high ice deformation, the effect on the model output from such events still would be negligible. However, in areas of low ice deformation, this effect could be substantial, unless the ice in the entire scene is elevated by the same amount, in which case there would be no relative change and associated phase response.

It is possible to retrieve sea level data from buoys or reanalysis data, which could be used to estimate surface lift due to tides and ocean surges, but will otherwise slightly reduce the model accuracy unless the pattern of a continuous lift can be recognized. 
The model resolution is a limitation with respect to the spatial scale of features that can be resolved. For PALSAR-1, a resolution much higher than 50x50 pixels $(\sim 750 \times 750 \mathrm{~m})$ would increase ambiguities of the model (along with sensitivity to noise) too much to get accurate results. Note, however, that the resolution could potentially be improved with higher resolution $\mathrm{C}$ - or $\mathrm{X}$-band systems. Being able to take advantage of multiple systems for increased coverage and resolution would also be beneficial for operational use.

The long repeat-pass time limits the interpretations to deformation accumulated over 46 days. In this study, the model can therefore not resolve short-term deformation events that occur on time scales on the order of hours to a few days. However, much of the deformation within the landfast ice is thermally driven and can therefore occur over days to weeks. Also, as a tool to evaluate whether a section of ice is landfast, it can be beneficial with longer temporal baselines to avoid mischaracterization of stationary pack ice [Mahoney et al., 2006]. PALSAR-2 became operational as of fall of 2014 with improved capabilities such as a shorter repeat cycle (14 days). However, suitable repeat pass Stripmap data have not yet been acquired with ALOS-2. The shorter temporal baseline of ALOS-2 has the potential for a higher temporal resolution of ice deformation and the coherence will likely be improved since surface deformation will be reduced over the shorter time period.

\section{Conclusions}

We have demonstrated that L-band PALSAR, with a 46-day temporal baseline, is capable of mapping small-scale deformation in three locations of the Alaska Beaufort Sea coast through the development of an inverse model. The displacements estimated from the 
model are consistent with known regional patterns of ice motion. This inverse modeling approach of InSAR outlined above provides an opportunity to study the interaction of stationary and near-stationary ice as a result of wind, ocean, and thermodynamic forcing at a level of detail and for a spatial coverage difficult to achieve in the past. The technique may furthermore be able to provide indirect insight into the sea-ice stress state as a result of such external forcing.

We have shown that the limitations of the modeling approach discussed can most often be overcome, retaining confidence in the model results, but we point out that ground validation would provide an additional tool to evaluate not only the model, but InSAR as a technique to monitor sea ice in general. Ground validation may also help understand the nature of higher-frequency displacements contributing to the interferograms.

This study demonstrates how InSAR can potentially increase understanding of sea ice on a fundamental level in terms of large-scale stability and long-term ice dynamics. Landfast ice is a critical resource and more information is needed to understand landfast ice formation and how it is impacted by changes in the environment such as by surrounding pack ice. To understand the future of the landfast ice and how large-scale sea ice changes may impact landfast ice properties important for stakeholders, landfast ice needs to be properly integrated into regional sea ice models currently depending on laboratory experiments [Hopkins, 2008]. However, higher-resolution datasets are needed for validation and ultimately improvement of landfast ice models [König Beatty, 2007]. This study demonstrates that InSAR opens up for a large-scale comparison between model and observations of landfast ice, a crucial step in validating landfast ice models. 
Landfast ice stability is not only important for industrial operations, but also for indigenous populations [Druckenmiller et al., 2013] and marine mammals [Smith, 1980]. This research explores InSAR as it provides valuable information to stakeholders, regulators and other decision-makers tracking the value of landfast ice as a hunting ground or as a habitat. To increase the value of InSAR in the context of sea ice use it will be important to further understand the rheology and yield stress on the scale of the landfast ice, and the temporal resolution needed to capture failure processes. An important next step will be to utilize the model developed here to quantify strain and internal ice stress and explore how the measured strains relate to destabilization of landfast ice and acting as potential precursor events for larger-scale failure and break-out [Dammann et al., In prep].

\section{Acknowledgements}

Part of this work was supported by the National Science Foundation as part of the Seasonal Ice Zone Observing Network (NSF-0856867). We would like to thank Peter Hickman at the Geographical Information Network of Alaska for programming support and Dr. Wenyu Gong at the Geophysical Institute, University of Alaska Fairbanks. Satellite data and guidance was provided by the Alaska Satellite Facility. Comments by three anonymous reviewers helped to substantially improve the manuscript.

\section{References}

Bamler, R., and P. Hartl (1998), Synthetic aperture radar interferometry, Inverse problems, 14(4), R1. 
Bamler, R., and M. Eineder (2005), Accuracy of differential shift estimation by correlation and split-bandwidth interferometry for wideband and delta-k SAR systems, Geoscience and Remote Sensing Letters, IEEE, 2(2), 151-155.

Bashaw, E. K., J. Drage, S. K. Lewis, and C. Billings (2013), Applied Ice Engineering for Exploring Arctic Natural Resources, paper presented at ISCORD 2013@ sPlanning for Sustainable Cold Regions, ASCE.

BP (2013), BPXA Winter Geotechnical Ancillary Activity Notification 2013, Rep., 22 pp.

Comiso, J. C., and D. K. Hall (2014), Climate trends in the Arctic as observed from space, Wiley Interdisciplinary Reviews: Climate Change, 5(3), 389-409.

Dammann, D. O., H. Eicken, A. Mahoney, and F. Meyer (In prep), Assessing landfast sea ice stability and internal ice stress around ice roads using L-band SAR interferometry and inverse modeling

Dammert, P. B. G., M. Lepparanta, and J. Askne (1998), SAR interferometry over Baltic Sea ice, Int J Remote Sens, 19(16), 3019-3037.

Dickins, D., G. Hearon, K. Morris, K. Ambrosius, and W. Horowitz (2011), Mapping sea ice overflood using remote sensing: Alaskan Beaufort Sea, Cold Reg Sci Technol, 65(3), 275-285.

Druckenmiller, M. L., H. Eicken, J. C. George, and L. Brower (2013), Trails to the whale: reflections of change and choice on an Iñupiat icescape at Barrow, Alaska, Polar Geography, 36(1-2), 5-29. 
Druckenmiller, M. L., H. Eicken, M. A. Johnson, D. J. Pringle, and C. C. Williams (2009), Toward an integrated coastal sea-ice observatory: System components and a case study at Barrow, Alaska, Cold Reg Sci Technol, 56(2-3), 61-72.

Eicken, H., and A. R. Mahoney (2015), Sea Ice: Hazards, Risks, and Implications for Disasters, Coastal and Marine Hazards, Risks, and Disasters, 381-399.

Eicken, H., A. L. Lovecraft, and M. L. Druckenmiller (2009), Sea-Ice System Services: A Framework to Help Identify and Meet Information Needs Relevant for Arctic Observing Networks, Arctic, 62(2), 119-136.

Eicken, H., G. R., H. T., J. M. A., L. A. L., and Kaufman M (2012), Automated ice mass balance site (SIZONET), edited, U. N.-C.-. ACADIS http://dx.doi.org/10.5065/D6MW2F2H.

Eicken, H., J. Jones, F. Meyer, A. Mahoney, M. L. Druckenmiller, M. Rohith, and C. Kambhamettu (2011), Environmental security in Arctic ice-covered seas: from strategy to tactics of hazard identification and emergency response, Mar Technol Soc J, 45(3), 3748.

Ferretti, A., A. Monti-Guarnieri, C. Prati, F. Rocca, and D. Massonet (2007), InSAR Principles-Guidelines for SAR Interferometry Processing and Interpretation, ESA Publications, TM-19.

Fienup-Riordan, A., and A. Rearden (2010), The ice is always changing: Yup'ik understandings of sea ice, past and present, in SIKU: knowing Our Ice: Documenting 
Inuit Sea Ice knowledge and Use, K. I, A. C, G. S, L. GJ and H. LK, 295-320, Springer, New York.

Finucane, R., and R. Scher (1983), Floating Ice Road Construction, Journal of Energy Resources Technology, 105(1), 26-29.

George, J. C., H. P. Huntington, K. Brewster, H. Eicken, D. W. Norton, and R. Glenn (2004), Observations on shorefast ice dynamics in Arctic Alaska and the responses of the Iñupiat hunting community, Arctic, 363-374.

Hilcorp (2015), Development and Production Plan, Liberty Development Project, Revision 1, 266.

Hopkins, M. A. (2008), Simulation of Landfast Ice Along the Alaskan Coast, 15 pp., US Army Cold Regions Research and Engineering Laboratory, US Department of the Interior, Minerals Management Service, Alaska OCS Region., New Hampshire Huang, L., D. Wolcott, and H. Yang (2011), Tidal Characteristics Along the Western and Northern Coasts of Alaska, paper presented at U.S. Hydro 2011 Conference, Florida.

König Beatty, C. (2007), Arctic landfast sea ice, Ph.D. thesis, New York University, 110.

Krieger, A. G., G. N. Kidd, and D. A. Cocking (2003), Northstar Drilling-Delivering the First Arctic Offshore Development, SPE drilling \& completion, 18(02), 188-193.

Li, S., L. Shapiro, L. McNutt, and A. Feffers (1996), Application of Satellite Radar Interferometry to the Detection of Sea Ice Deformation, Journal of the Remote Sensing Society of Japan, 16(2), 67-77. 
Mahoney, A., H. Eicken, and L. Shapiro (2007), How fast is landfast sea ice? A study of the attachment and detachment of nearshore ice at Barrow, Alaska, Cold Reg Sci Technol, 47(3), 233-255.

Mahoney, A., H. Eicken, L. Shapiro, and A. Graves (2006), Defining and locating the seaward landfast ice edge in northern Alaska, paper presented at 18th International Conference on Port and Ocean Engineering under Arctic Conditions (POAC'05), Potsdam, NY.

Mahoney, A., H. Eicken, A. G. Gaylord, and R. Gens (2014), Landfast sea ice extent in the Chukchi and Beaufort Seas: The annual cycle and decadal variability, Cold Reg Sci Technol, 103, 41-56.

Mahoney, A., D. O. Dammann, M. A. Johnson, H. Eicken, and F. J. Meyer (2016), Measurement and imaging of infragravity waves in sea ice using InSAR, Geophys Res Lett.

Meier, W. N., G. K. Hovelsrud, B. E. Oort, J. R. Key, K. M. Kovacs, C. Michel, C. Haas, M. A. Granskog, S. Gerland, and D. K. Perovich (2014), Arctic sea ice in transformation: A review of recent observed changes and impacts on biology and human activity, Reviews of Geophysics, 52(3), 185-217.

Mesher, D., S. Proskin, and E. Madsen (2008), Ice road assessment, modeling and management, paper presented at 7th International Conference on Managing Pavement Assets, Calgary, AB. 
Meyer, F. J., A. R. Mahoney, H. Eicken, C. L. Denny, H. C. Druckenmiller, and S. Hendricks (2011), Mapping arctic landfast ice extent using L-band synthetic aperture radar interferometry, Remote Sens Environ, 115(12), 3029-3043.

Morris, K., S. Li, and M. Jeffries (1999), Meso-and microscale sea-ice motion in the East Siberian Sea as determined from ERS-I SAR data, Journal of Glaciology, 45(150), 370383.

Potter, R., J. Walden, and R. Haspel (1981), Design and construction of sea ice roads in the Alaskan Beaufort Sea, paper presented at Offshore Technology Conference, Offshore Technology Conference, Houston, Texas.

Scharroo, R., and P. Visser (1998), Precise orbit determination and gravity field improvement, Journal of Geophysical Research, 103(C4), 8113-8127.

Smith, T. G. (1980), Polar bear predation of ringed and bearded seals in the land-fast sea ice habitat, Canadian Journal of Zoology, 58(12), 2201-2209.

Stroeve, J. C., M. C. Serreze, M. M. Holland, J. E. Kay, J. Malanik, and A. P. Barrett (2012), The Arctic's rapidly shrinking sea ice cover: a research synthesis, Climatic Change, 110(3-4), 1005-1027.

Tucker, W., W. Weeks, A. Kovacs, and A. Gow (1980), Nearshore ice motion at Prudhoe Bay, Alaska, in Sea ice processes and models: proceedings of the Arctic Ice Dynamics Joint Experiment International Commission of Snow and Ice symposium P. RS, 261-272, University of Washington Press, Seattle, Washington. 
USACE (2002), Ice Engineering, Rep., 475 pp, Department of the Army, US Army Corps of Engineers Washington DC.

Vincent, F., D. Raucoules, T. Degroeve, G. Edwards, and M. Abolfazl Mostafavi (2004), Detection of river/sea ice deformation using satellite interferometry: limits and potential, Int J Remote Sens, 25(18), 3555-3571.

Weber Hoen, E., and H. A. Zebker (2000), Penetration depths inferred from interferometric volume decorrelation observed over the Greenland ice sheet, IEEE Transactions on Geoscience and Remote Sensing 38(6), 2571-2583.

Weeks, W. (1977), Studies of the movement of coastal sea ice near Prudhoe Bay, Alaska, USA, Journal of Glaciology, 19(81), 533-546.

Weeks, W. (2010), On sea ice, University of Alaska Press, Fairbanks, Alaska, 664 pp.

Weingartner, T. J., S. L. Danielson, J. L. Kasper, and S. R. Okkonen (2009), Circulation and Water Property Variations in the Nearshore Alaskan Beaufort Sea (1999-2007), 168 pp., US Dept. of Interior, Minerals Management Service, Alaska Outer Continental Shelf Region, Anchorage, Alaska.

\section{Captions}

Figure 1: The areas covered by the three interferograms used in this study are shown in blue shading with the specific study areas outlined in red. The regional data availability of ALOS-I PALSAR-I in the middle of the landfast ice season (strictly within JanuaryApril 2010) is shown in gray. The spring monthly mean (1996-2008) landfast sea ice 
extent is indicated with colored lines [Mahoney et al., 2014].

Figure 2: Example of landfast sea ice where different regimes possess different levels of stability.

Figure 3: Interferogram workflow outlining steps from two raw single-look complex (SLC) images to a geocoded interferogram.

Figure 4: Modes and directions of deformations modeled are displayed in the left column. Modes include divergence, rotation, shear, uni-axial divergence, and surface tilt. These displacements are modeled for 16 look angles varying at 22.5-degree intervals. Rotation and radial convergence are directionally independent. Uni-axial divergence is correlated with reversed directions. Shear and uni-axial divergence in cross-track direction is completely correlated with rotation and radial divergence respectively. Surface tilt is indicated by brighter (darker shading) representing higher (lower) elevation. The corresponding modeled interferograms are displayed in the right column.

Figure 5: Correlation matrix between the 44 deformation modes (including different angles unless not unique). White lines distinguish between different modes of deformation. Some of the deformation modes produce highly correlated interferograms in particular between shear and uni-axial divergence.

Figure 6: The figure indicates the correlation between an example patch of an observed interferogram and all 44 modeled interferograms (indicated mode above and direction of motion below the correlation map along with the color used to display the particular mode combination) and for 20 displacement gradients. In this case, 45 degree angled sinistral shear with a displacement gradient of $\sim 1 \mathrm{~m}$ (from center to corner of a 50x50- 
pixel patch) is the most likely possibility (due to geophysical constraints - see Section 4.2). Uni-axial convergence and vertical incline towards the upper right corner is also a possibility with almost equal correlation.

Figure 7: (a) Amplitude image over Elson Lagoon, Alaska (27 Dec 2009). The land is masked out in black. (b-d) Interferograms created from the following consecutive acquisition pairs.

Figure 8: (a) The model results display deformation mode with colors corresponding to the specific combinations of deformation mode. Light and dark purple correspond to modes that are independent of the viewing angle, including radial divergence and rotation, respectively. Yellow and orange colors indicate left-handed (sinistral) shear and uni-axial convergence or divergence, respectively. Blue and cyan indicate right-handed (dextral) shear and uni-axial divergence or convergence, respectively. The lines indicate lines of equal deformation (parallel to shear and perpendicular to uni-axial divergence) and " $\mathrm{x}$ " and " $\mathrm{o}$ " correspond to divergence / counter clockwise rotation and convergence / clockwise rotation respectively. (b) Energy of the model results indicating certainty of the model (see Section 3.2 for details). White colors in figure c correspond to where energy did not exceed 0.7 .

Figure 9: (a) Amplitude image for the Northstar Island (circled) and Prudhoe Bay region, Alaska (21 Mar 2010) (arrow pointing to the ice road connecting the island to the mainland) and (b) the interferogram created from this and the following acquisition (6 May 2010) (arrow pointing to boundary between high and low fringe density at Northstar 
Island). (c) The model results display deformation mode with colors corresponding to the specific combination of deformation modes. The lines indicate lines of equal deformation (parallel to shear and perpendicular to uni-axial divergence) and " $\mathrm{x}$ " and "o" correspond to divergence / counter clockwise rotation and convergence / clockwise rotation respectively. (d) Energy of the model results indicating certainty of the model (see Section 3.2 for details). White colors in figure c correspond to where energy did not exceed 0.7 .

Figure 10: Incoherent cross-correlation displacement vectors superimposed on the interferogram coherence over Northstar (21 Mar 2010 - 6 May 2010). The ice road is apparent as an area of reduced coherence due to ongoing road construction (snow removal and thickening of the ice through pumping of water onto the ice surface). The vectors indicate a large area of uniform left-handed (sinistral) shear motion.

Figure 11: (a) Amplitude image over Foggy Island Bay and the Liberty prospect (Liberty is roughly indicated with a circle and Endicott is marked with an arrow) near Prudhoe Bay, Alaska (3/31/2010) and (b) the interferogram created from this and the following acquisition (5/16/2010). (c) The model results display direction of surface tilt with arrows pointing towards higher elevation. The model is set to only match vertical displacement. (d) Energy of the model results. White cells in Figure 11c correspond to an energy of 0.7 or less. 